\title{
Analysis of Complex Transportation Network and Its Tourism Utilization Potential: A Case Study of Guizhou Expressways
}

\author{
Sihong Chen $\left(\mathbb{D},{ }^{1,2}\right.$ Jianchao Xi $\left(\mathbb{D},{ }^{1}\right.$ Menghao Liu $\left(\mathbb{D},{ }^{1,2}\right.$ and Tao Li $\mathbb{D i D}^{3}$ \\ ${ }^{1}$ Key Laboratory of Regional Sustainable Development Modeling, \\ Institute of Geographic Sciences and Natural Resources Research, Chinese Academic of Sciences, Beijing 100101, China \\ ${ }^{2}$ College of Resources and Environment, University of Chinese Academy of Sciences, Beijing 100049, China \\ ${ }^{3}$ Institute of Finance and Banking, Chinese Academy of Social Sciences, Beijing 100028, China \\ Correspondence should be addressed to Jianchao Xi; xijc@igsnrr.ac.cn
}

Received 31 March 2020; Revised 10 May 2020; Accepted 12 May 2020; Published 6 July 2020

Guest Editor: Wen-Ze Yue

Copyright (c) 2020 Sihong Chen et al. This is an open access article distributed under the Creative Commons Attribution License, which permits unrestricted use, distribution, and reproduction in any medium, provided the original work is properly cited.

\begin{abstract}
Transportation is an example of a typical, open, fluid complex network system. Expressways are one form of complex transportation networks, and expressway service areas serve as infrastructure nodes in the expressway transportation network; hence, their construction has a significant impact on tourism development and utilization. Domestic and foreign studies on complex transportation networks have mostly been conducted from the perspective of railways, air transport, and urban transportation but seldom on expressway transportation networks. This study employed complex network theory, social network analysis, kernel density analysis, and bivariate autocorrelation to characterize the spatial structure of expressway transport networks in terms of geographical centrality. By innovating the coupling of geographical centrality and passenger flow centrality in clustering, the study also quantitatively analyzed the differences between the geographical advantage and actual passenger flow advantage of China's Guizhou expressway transportation network to analyze the tourism utilization potential of expressway service areas. We found that (1) the geographical centrality of the Guizhou expressway transportation network ranged from -1.28 to 3.33 , and its distribution shows a single-core, polyconcentric dispersed spatial structure; (2) the passenger-car flow rate ranged from 15,000 to 3.66 million, and its distribution showed a dual-core, polycentric dispersed structure that is weakly concentric; and (3) there was a positive correlation of 0.22 between the geographical centrality and passenger flow of the Guizhou expressway transportation network, which showed seven cluster types-"high-high," "moderately high-high," "low-high," "moderately low-high," "highlow," "moderately high-low," and "low-low"-for which seven corresponding models of tourism development were proposed. This study broadens the practical application of traffic network complexity research and provides a scientific basis for upgrading and transforming the Guizhou expressway transportation network as well as for developing composite tourism uses for expressway service areas.
\end{abstract}

\section{Introduction}

Transportation is one of the six elements of tourism development and the most important intermediary component in the "three-body theory of tourism." [1] As the main transport corridor for self-driving tourism, expressways play an important role in improving interregional accessibility. With the gradual construction of the "fast forward, slow travel" expressway network, service areas have become part of their infrastructure, and their tourism service functions have expanded and matured. To enable tourists to receive high-quality, convenient, and efficient services, it is necessary to tap the development potential of expressway service areas by reviewing, upgrading, and shaping them into tourist destinations. Doing so will achieve integrated development between expressway service areas and the tourism and leisure industries, which is an important facet of the transportation-tourism relationship.

As the scale of transportation networks expands and their degree of complexity increases, research on transportation network complexity has become an important means to understand the spatial structure and organizational 
characteristics of transportation networks. A series of network analysis tools, such as multiple centrality assessment (MCA) [2], urban network analysis (UNA) [3], and spatial design network analysis (sDNA) [4], have been proposed, which have facilitated the computation and analysis of the morphological characteristics of complex transportation networks. Western scholars investigating complex transportation networks have mostly explored the centrality distribution of transportation hubs from the perspectives of railway [5, 6], air transport [7-10], and urban transportation [11-13] and have used transportation networks to analyze destination accessibility and the optimization of spatial structures [14, 15]. In contrast, scholars in China have primarily employed transportation network centrality, complexity, and other indicators to study the evolution of the structural characteristics [16] and spatial accessibility $[17,18]$ of high-speed rail [19], air [20, 21], subway [22, 23], and other traffic networks [24-26].

Transportation networks were first employed in tourism research in the 1920s. Western scholars initially explored them from the perspective of tourism transportation planning $[27,28]$ followed by an increasing research emphasis on the impact of transportation on tourism demand [29]. The emergence of different transportation modes, such as air transport and high-speed rail, led to changes in the accessibility of tourist destinations [30-33], which affected the spatial behavior and migration patterns of tourists [34-36]. Furthermore, continuous improvements to transportation conditions also resulted in a continual enhancement of tourists' tourism experience and transportation satisfaction [37]. Meanwhile, environmental [38-40], noise $[41,42]$, and congestion [43] problems in the transportation network have affected the sustainable development of tourism. In China, as the tourism industry developed, scholars in the 1980s began to explore the relationship between transportation and tourism [44]. The degree of transportation convenience became an important indicator for the development of the tourism industry [45], and changes in transportation facilities also affected the spatial structure of regional tourist destinations [46, 47]. Methods such as social network analysis, analytic hierarchy process, and TOP network were used to quantitatively investigate the relationship between tourism and complex transportation networks [48, 49], and the environmental impact of tourism transportation systems was calculated using ecological footprint, carbon emissions, and other indicators [50]. Furthermore, scenic byways were innovatively defined as tourist attractions for planning and evaluation [51].

As self-driving tourism has developed into an increasingly common phenomenon, expressways have become an indispensable and vital link in tourism development, making it crucial to perform timely complex network analysis on expressways and study their tourism utilization potential. Though several studies have been conducted in China and abroad on the impact of transportation networks on tourism [27-51], research on the relationship between expressway transportation networks and tourism is lacking. Thus, this study examined the expressway transportation network in Guizhou province using complex network theory, social network analysis, kernel density analysis, and bivariate autocorrelation to calculate the spatial clustering of geographical centrality and passenger flow centrality, quantitatively evaluate the difference between geographical advantage and actual passenger flow advantage, and analyze the tourism utilization potential of expressway service areas. Based on the results, seven models of tourism development were proposed, with a view of providing a scientific basis for optimizing the layout of expressway transportation networks and reshaping service areas for tourism.

\section{Data and Methods}

2.1. Study Area. Guizhou province is located in the inland southwestern region of China at a longitude of $103^{\circ} 36^{\prime}-109^{\circ} 35^{\prime}$ and a latitude of $24^{\circ} 37^{\prime}-29^{\circ} 13^{\prime}$ (Figure 1). It covers a total area of $176,200 \mathrm{~km}^{2}$, and $92.5 \%$ is composed of mountainous and hilly areas including plateaus. Guizhou province is a world-famous mountain tourism destination, also known as the "Mountain Park Province" and the "Summer Capital of China." Due to its unique mountainous terrain, expressways have become the region's main transport corridor. The province has $6,450 \mathrm{~km}$ of expressways connecting 71 national and provincial scenic areas, and all $5 \mathrm{~A}$ and most $3 \mathrm{~A}$ and $4 \mathrm{~A}$ scenic areas in the province are located within 30 minutes of expressway-connected areas. This has provided the facility guarantee and the tourist source needed for the integrated development of mountain tourism and expressway service areas.

2.2. Data Source. The first-hand data for this study came from field surveys and investigations of 65 pairs of expressway service areas in Guizhou that were randomly selected by our research team based on the principle of regional averaging. The manager of each expressway service area provided our team with basic information such as the passenger flow rate, deviations in different flow directions, and construction of service areas. Our second-hand data came from the passenger-car flow rate and vehicle registration data at each expressway section for February 3, May 1, June 9, August 1, October 1, and December 3, 2018, which were provided by the Guizhou Provincial Department of Transportation, and two schematic diagrams-one showing the distribution of expressway service areas and parking areas across Guizhou in 2019 and the other showing the expressway operation units across Guizhou in 2017. We also obtained the 2018 Google Earth images with a spatial resolution of $0.6 \mathrm{~m}$, on which ArcGIS vectorization was performed to obtain a map of expressways in Guizhou.

\subsection{Methods}

2.3.1. Social Network Analysis. Social network analysis primarily consists of three basic centrality indicators-degree, closeness, and betweenness centrality [52]-which were used to measure the connectivity, accessibility, and intermediation, respectively, of expressway transportation networks. These were applied to the expressway network in 


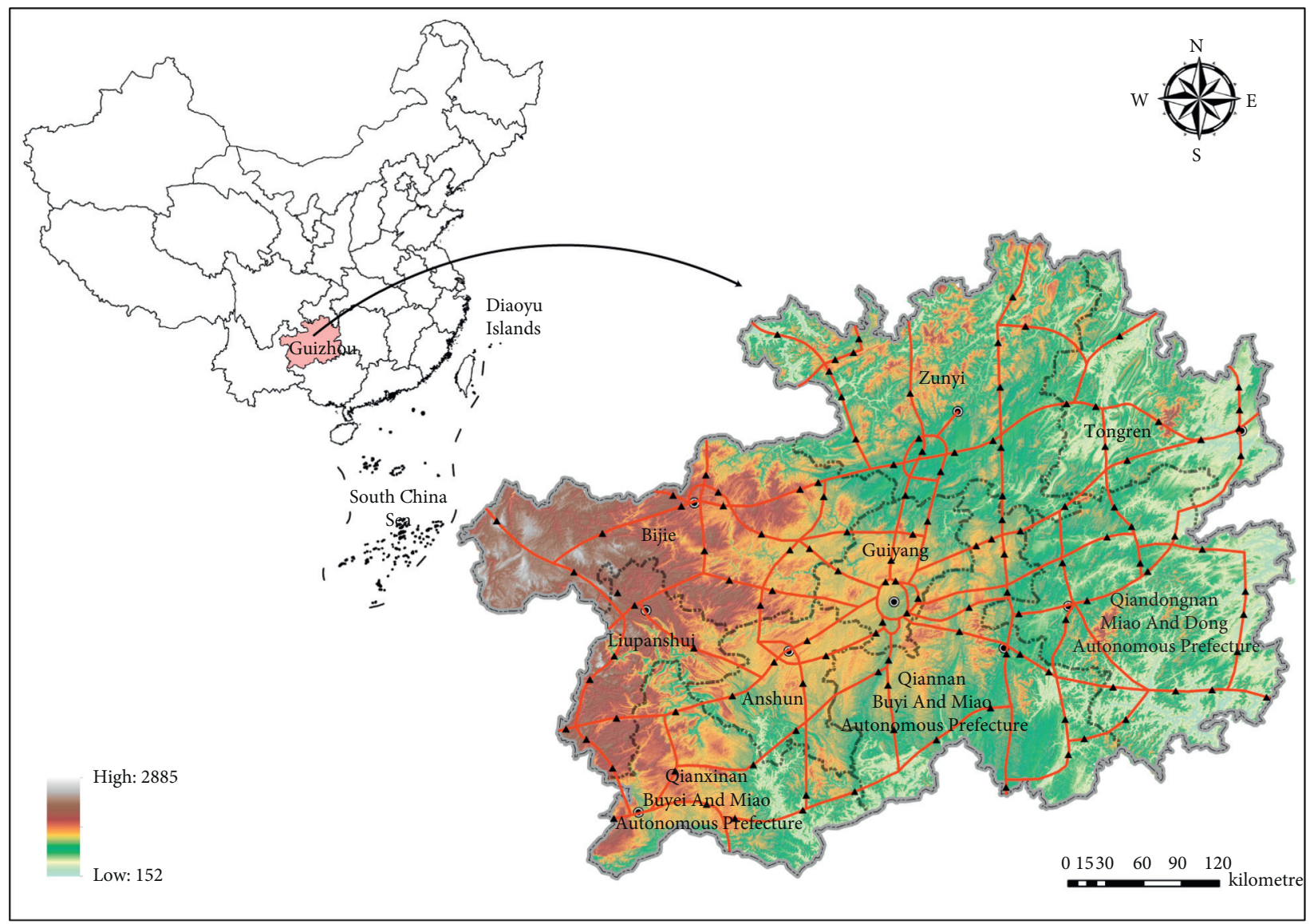

- Provincial capital ----- City boundary

- Provincial boundary

Figure 1: Location of the study area (Guizhou, China).

Guizhou province through Ucinet (Borgatti, S.P., Everett, M.G., and Freeman, L.C. Released 2002. Ucinet 6 for Windows: Software for Social Network Analysis. Harvard, MA: Analytic Technologies) calculations and then converted using factor analysis in SPSS (IBM Corp. Released 2017. IBM SPSS Statistics 25.0 for Windows. Armonk, NY: IBM Corp.) into geographical centrality, which provided a basis to quantitatively investigate the relationship between geographical centrality and passenger flow centrality.

Degree centrality (hereafter, $D$ ) measures the number of direct links to a node and is calculated by the following equation [52]:

$$
D=\frac{x}{(n-1)}
$$

In (1), $n$ is the number of nodes and $x$ is the number of links between a given node and other nodes.

Closeness centrality (hereafter, $C$ ) measures the average length of the shortest distance between each node pair and is calculated by the following equation $[12,52]$ :

$$
C=\frac{(n-1)}{\sum_{j=1}^{n} d_{i j}} .
$$

In (2), $d_{i j}$ is the shortest distance between nodes $i$ and $j$.
Betweenness centrality (hereafter, $B$ ) measures the number of times a node is traversed on the shortest path between other nodes and is calculated by the following equation $[12,52]$ :

$$
B=\frac{2 \sum_{a}^{n} \sum_{b}^{n} g_{a b}(i) / g_{a b}}{n^{2}-3 n+2} .
$$

In (3), $g_{a b}$ is the shortest path between nodes $a$ and $b$, and $g_{a b}(i)$ is the number of times $i$ is traversed on the shortest path between $a$ and $b$, where $a \neq b \neq i, a<b$.

In the network structure, degree centrality, closeness centrality, and betweenness centrality calculate the convenience, accessibility, and intermediary of network nodes from three perspectives [52]. Any centrality can only reflect one side of the network structure and cannot reflect the overall characteristics of the network space structure. To represent the geographical location features of the network structure in a unified way, this study puts forward the overall features of the geographical location of the network structure reflected by geographical centrality. Geographical centrality refers to the degree of a node's location center in the whole network, which is a unified indicator of network structure convenience, accessibility, and intermediation based on three network centricity characteristics: degree 
centrality, closeness centrality, and betweenness centrality. The higher the geographical centrality value, the better the location of the node in the network structure.

Considering that degree centrality, closeness centrality, and betweenness centrality are representative and there is a certain correlation among them that meets the calculation conditions of factor analysis, factor analysis in SPSS was used to calculate the weight index of the three types of centrality. Because the range of values for degree centrality, closeness centrality, and betweenness centrality is quite different, $Z$ score is used to standardize and obtain normalized values for the three indexes.

Geographical centrality (hereafter, $G$ ) is calculated as follows:

$$
\begin{aligned}
G & =\left(w_{D} \times y_{D i}+w_{C} \times y_{C i}+w_{B} \times y_{B i}\right) . \\
y_{D i} & =\frac{x_{D i}-\overline{x_{D}}}{s_{D}}, \\
\overline{x_{D}} & =\frac{\sum_{i=1}^{n} x_{D i}}{n}, \\
s_{D} & =\sqrt{\frac{1}{n-1} \sum_{i=1}^{n}\left(x_{D i}-\overline{x_{D}}\right)^{2},} \\
y_{C i} & =\frac{x_{C i}-\overline{x_{C}}}{s_{C}}, \\
\overline{x_{C}} & =\frac{\sum_{i=1}^{n} x_{C i}}{n}, \\
s_{C} & =\sqrt{\frac{1}{n-1} \sum_{i=1}^{n}\left(x_{C i}-\overline{x_{C}}\right)^{2}}, \\
s_{B} & =\sqrt{\frac{1}{n-1} \sum_{i=1}^{n}\left(x_{B i}-\overline{x_{B}}\right)^{2} .} \\
y_{B i} & =\frac{x_{B i}-\overline{x_{B}}}{s_{B}}, \\
\sum_{i=1}^{n} x_{B i} & \\
n &
\end{aligned}
$$

In (4)-(7), $w_{D}, w_{C}$, and $w_{B}$ are the weights of degree centrality, closeness centrality, and betweenness centrality, which can be obtained by factor analysis. $y_{D i}, y_{C i}$, and $y_{B i}$ are the normalized values for degree centrality, closeness centrality, and betweenness centrality, which can be obtained from a Z-score standardization calculation, where $\overline{x_{D}, x_{C}}$, and $\overline{x_{B}}$ are the mean values and $s_{D}, s_{C}$, and $s_{B}$ are the standard deviations [53].

2.3.2. Kernel Density Analysis. Passenger flow centrality is expressed by the total number of passenger cars passing through the expressway section where the service areas are located. It is an important factor affecting the reception and provision of tourism services by service areas. ArcGIS
(Environmental Systems Research Institute (ESRI). Released 2014. ArcGIS 10.2 for Desktop. Redlands, CA: ESRI) was used to input the data on passenger-car flow rates for each expressway section into the vector database, and the kernel density plot of the passenger-car flow rate was computed using spatial kernel density analysis.

The kernel density is calculated as follows [54-56]:

$$
\begin{aligned}
\widehat{f(x)} & =\frac{1}{n h^{2} \pi} \sum_{i=1}^{n}\left[1-\frac{\left(x-x_{i}\right)^{2}-\left(y-y_{i}\right)^{2}}{h^{2}}\right]^{2}, \\
h & =0.9 * \min \left(S D, \sqrt{\frac{1}{\ln 2}} * D_{m}\right) * n^{-0.2} .
\end{aligned}
$$

In (8), $n$ is the number of nodes in the service area of the expressway network, $h$ is the bandwidth, and $\left(x-x_{i}\right)^{2}-$ $\left(y-y_{i}\right)^{2}$ is the deviation between $\left(x_{i}, y_{i}\right)$ and $(x, y)$.

In (9), SD is the standard distance, and $D_{m}$ is the median distance.

2.3.3. Bivariate Spatial Autocorrelation Analysis. Tourism utilization potential was evaluated using the consistency in the spatial distribution between geographical centrality and passenger flow centrality, which was determined using coupling analysis spatial autocorrelation based on GeoDa (Luc Anselin. Released 2019. GeoDa 1.14 for Windows. Chicago, IL: Luc Anselin). This included both global and local spatial autocorrelation.

The equation for global spatial autocorrelation is given as follows [57]:

$$
I_{1}=\frac{n \sum_{i=1}^{n} \sum_{j=1}^{n} C_{i j} z_{i} z_{j}}{\sum_{i=1}^{n} \sum_{j=1}^{n} C_{i j} \sum_{i=1}^{n} z_{i}^{2}} .
$$

In (10), $C_{i j}$ is the spatial weight between $i$ and $j$, and $z_{i}$ and $z_{j}$ are the deviations of attributes $i$ and $j$ from the mean.

The equation for local spatial autocorrelation is given as follows $[57,58]$ :

$$
I_{2}=\frac{X_{k}^{i}-\overline{X_{k}}}{\sigma_{k}} \sum_{j=1}^{n} C_{i j} \frac{\left(X_{l}^{j}-\overline{X_{l}}\right)}{\sigma_{l}} .
$$

In (11), $X_{k}^{i}$ is the value of attribute $i$ at $k ; X_{l}^{j}$ is the value of attribute $j$ at $l$; and $\sigma_{k}$ and $\sigma_{l}$ are the variances of attributes $k$ and $l$.

\section{Analysis of Results}

\subsection{Distribution Characteristics of Geographical Centrality}

3.1.1. Degree Centrality. Based on calculations using formula (1), we can see from Figure 2 and Table 1 that the degree of the Guizhou expressway transportation network ranges from 0 to 0.07 . Its distribution shows a clear polycentric clustered structure, with the expressway service areas around Guiyang (Area A), Bijie (Area B), and Zunyi (Area C) showing the highest levels of degree centrality and being primarily concentrically distributed. Area A is the primary 


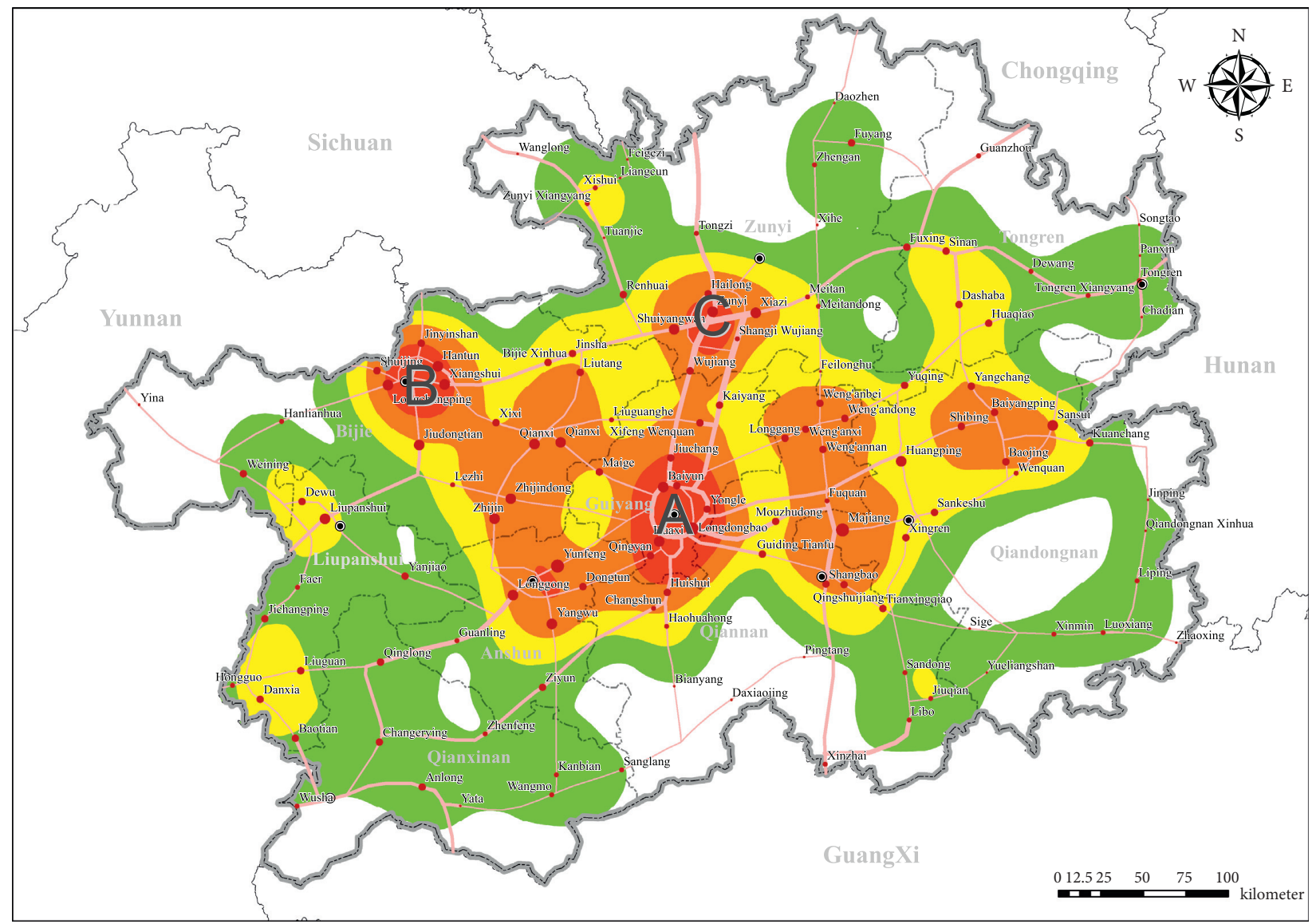

\footnotetext{
- Provincial capital

---- Provincial boundary

----- City boundary

—_ Expressway
}

Degree centrality

- 0.008-0.016

- $0.017-0.024$

- $0.025-0.040$

- 0.041-0.056

- $0.057-0.073$
Degree kernel density

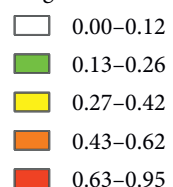

Figure 2: Kernel density plot of degree in the Guizhou expressway network.

core region of the overall network with respect to degree and is mainly distributed around Guiyang. The Longdongbao and Yunfeng service areas have the highest number of direct links to other nodes, both with a degree of 0.0726 . These are the service areas with the best transportation accessibility and convenience in Guizhou province. Areas B and C are secondary core regions and are distributed around Bijie and Zunyi. The degrees of service areas within these regions, including Hantun, Xiangshui, Jiudongtian, and Shuiyangwan, are $0.05-0.07$. Their transportation accessibility and convenience are second only to the Longdongbao and Yunfeng service areas. The degree of $50.4 \%$ of service areas ranges between 0.03 and 0.05 and that of $39.20 \%$ of service areas ranges between 0.01 and 0.03 . These service areas have average transportation accessibility and are considered transitional service areas between the core and peripheral regions. The degrees of the Feigezi, Daxiaojing, Daozhen, and Songtao service areas are only 0.0081 , and they have the lowest transportation convenience. These service areas have the fewest direct links with other service areas in the entire expressway transportation network.

The degree of the expressway transportation network in Guizhou province shows a polycentric distribution, with the three high-value areas (Guiyang, Bijie, and Zunyi) forming the core from which the degree gradually declines as we move outward to the periphery. The degree of Guiyang is far higher than that of Bijie and that of Zunyi; therefore, the core transportation hub is mainly located in the Guiyang urban area.

3.1.2. Closeness Centrality. Based on calculations using formula (2), we can see from Figure 3 and Table 2 that the closeness of the Guizhou expressway transportation network ranges between 9 and 25. Its distribution shows a "coreperiphery-margin" spatial structure. Area A is the core 
TABle 1: Degree of expressway service areas in Guizhou province.

\begin{tabular}{|c|c|}
\hline Name & Degree \\
\hline Longdongbao & 0.0726 \\
\hline Yunfeng & 0.0726 \\
\hline Majiang & 0.0645 \\
\hline Hantun & 0.0565 \\
\hline Xiangshui & 0.0565 \\
\hline Jiudongtian & 0.0565 \\
\hline Zhijindong & 0.0565 \\
\hline Shuiyangwan & 0.0565 \\
\hline Huaxi & 0.0565 \\
\hline Longchangping & 0.0484 \\
\hline Liupanshui & 0.0484 \\
\hline Zhijin & 0.0484 \\
\hline Qianxi & 0.0484 \\
\hline Zunyi & 0.0484 \\
\hline Xiazi & 0.0484 \\
\hline Baiyun & 0.0484 \\
\hline Longgong & 0.0484 \\
\hline Yangwu & 0.0484 \\
\hline Huangping & 0.0484 \\
\hline Sansui & 0.0484 \\
\hline Shuijing & 0.0403 \\
\hline Jinyinshan & 0.0403 \\
\hline Maige & 0.0403 \\
\hline Liutang & 0.0403 \\
\hline Xifeng Wenquan & 0.0403 \\
\hline Huoshipo & 0.0403 \\
\hline Yongle & 0.0403 \\
\hline Dongtun & 0.0403 \\
\hline Changerying & 0.0403 \\
\hline Huishui & 0.0403 \\
\hline Shangbao & 0.0403 \\
\hline Longgang & 0.0403 \\
\hline Sinan & 0.0403 \\
\hline Dashaba & 0.0403 \\
\hline Yuqing & 0.0403 \\
\hline Baiyangping & 0.0403 \\
\hline Shibing & 0.0403 \\
\hline Baojing & 0.0403 \\
\hline Sankeshu & 0.0403 \\
\hline Weining & 0.0323 \\
\hline Dewu & 0.0323 \\
\hline Jichangping & 0.0323 \\
\hline Yanjiao & 0.0323 \\
\hline Xixi & 0.0323 \\
\hline Bijie Xinhua & 0.0323 \\
\hline Jinsha & 0.0323 \\
\hline Renhuai & 0.0323 \\
\hline Hailong & 0.0323 \\
\hline Wujiang & 0.0323 \\
\hline Kaiyang & 0.0323 \\
\hline Jiuchang & 0.0323 \\
\hline Qingyan & 0.0323 \\
\hline Qinglong & 0.0323 \\
\hline Liuguan & 0.0323 \\
\hline Danxia & 0.0323 \\
\hline Baotian & 0.0323 \\
\hline Ziyun & 0.0323 \\
\hline Anlong & 0.0323 \\
\hline Qingshuijiang & 0.0323 \\
\hline Tianxingqiao & 0.0323 \\
\hline Guiding Tianfu & 0.0323 \\
\hline Mouzhudong & 0.0323 \\
\hline
\end{tabular}

TABle 1: Continued.

\begin{tabular}{|c|c|}
\hline Name & Degree \\
\hline Weng'annan & 0.0323 \\
\hline Weng'anxi & 0.0323 \\
\hline Weng'andong & 0.0323 \\
\hline Weng'anbei & 0.0323 \\
\hline Fuxing & 0.0323 \\
\hline Fuyang & 0.0323 \\
\hline Huaqiao & 0.0323 \\
\hline Yangchang & 0.0323 \\
\hline Kuanchang & 0.0323 \\
\hline Xingren & 0.0323 \\
\hline Hanlianhua & 0.0242 \\
\hline Faer & 0.0242 \\
\hline Lezhi & 0.0242 \\
\hline Liuguanghe & 0.0242 \\
\hline Xishui & 0.0242 \\
\hline Zunyi Xiangyang & 0.0242 \\
\hline Tongzi & 0.0242 \\
\hline Shangji Wujiang & 0.0242 \\
\hline Guanling & 0.0242 \\
\hline Hongguo & 0.0242 \\
\hline Wusha & 0.0242 \\
\hline Zhenfeng & 0.0242 \\
\hline Kanbian & 0.0242 \\
\hline Wangmo & 0.0242 \\
\hline Sanglang & 0.0242 \\
\hline Changshun & 0.0242 \\
\hline Haohuahong & 0.0242 \\
\hline Xinzhai & 0.0242 \\
\hline Libo & 0.0242 \\
\hline Jiuqian & 0.0242 \\
\hline Sandong & 0.0242 \\
\hline Xinmin & 0.0242 \\
\hline Luoxiang & 0.0242 \\
\hline Liping & 0.0242 \\
\hline Fuquan & 0.0242 \\
\hline Meitandong & 0.0242 \\
\hline Meitan & 0.0242 \\
\hline Zhengan & 0.0242 \\
\hline Guanzhou & 0.0242 \\
\hline Dewang & 0.0242 \\
\hline Tongren Xiangyang & 0.0242 \\
\hline Wenquan & 0.0242 \\
\hline Tongren & 0.0242 \\
\hline Yina & 0.0161 \\
\hline Wanglong & 0.0161 \\
\hline Tuanjie & 0.0161 \\
\hline Liangcun & 0.0161 \\
\hline Yata & 0.0161 \\
\hline Bianyang & 0.0161 \\
\hline Pingtang & 0.0161 \\
\hline Sige & 0.0161 \\
\hline Yueliangshan & 0.0161 \\
\hline Zhaoxing & 0.0161 \\
\hline Feilonghu & 0.0161 \\
\hline Xihe & 0.0161 \\
\hline Panxin & 0.0161 \\
\hline Chadian & 0.0161 \\
\hline Jinping & 0.0161 \\
\hline Qiandongnan Xinhua & 0.0161 \\
\hline Feigezi & 0.0081 \\
\hline Daxiaojing & 0.0081 \\
\hline Daozhen & 0.0081 \\
\hline Songtao & 0.0081 \\
\hline
\end{tabular}




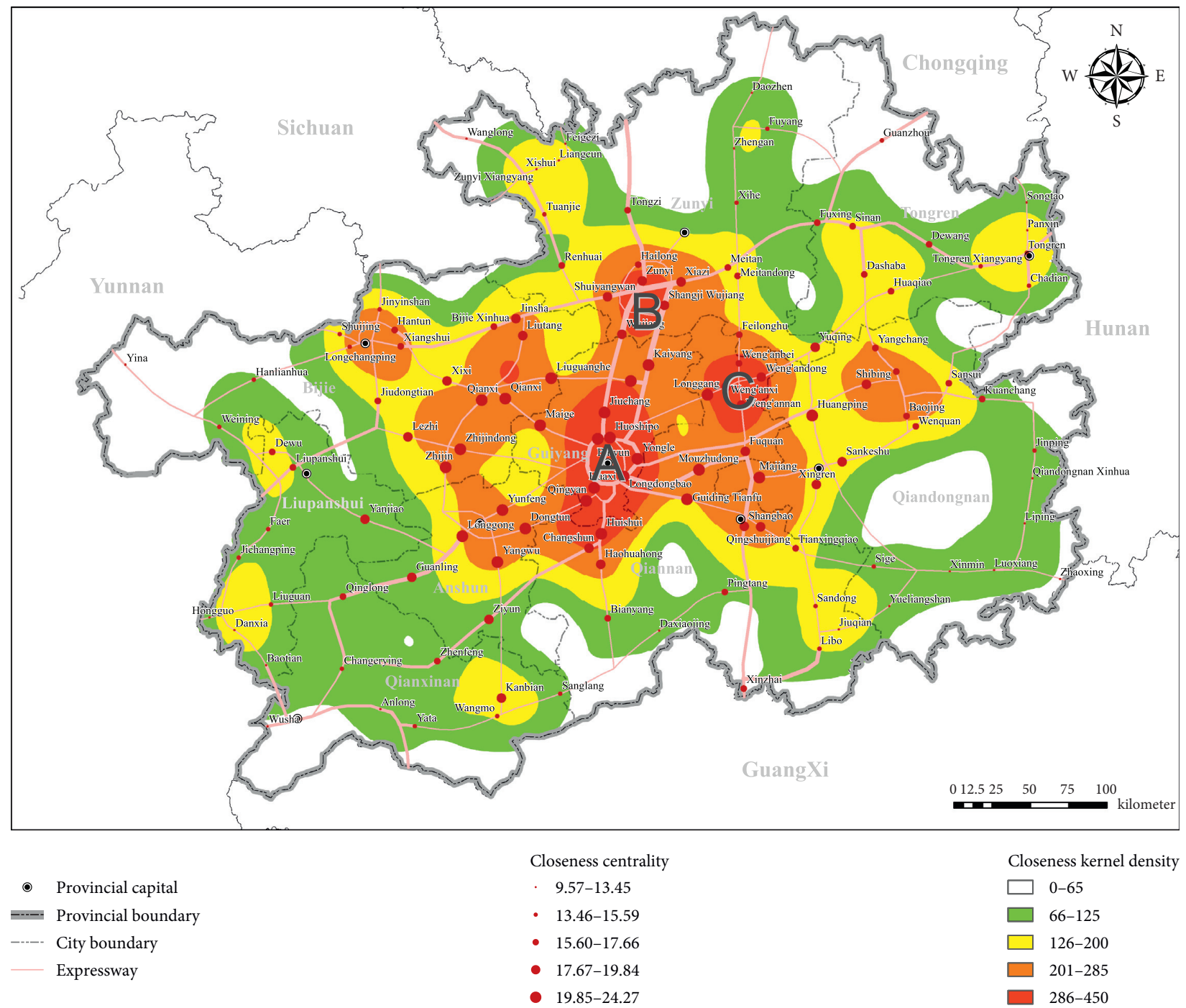

Figure 3: Kernel density plot of closeness in the Guizhou expressway network.

region with high values of closeness and is mainly located in the south of Guiyang and northwest of Qiannan. The closeness of the Longdongbao, Yunfeng, Yongle, Huoshipo, Huaxi, and Baiyun service areas is all above 20. Among them, the closeness of the Longdongbao service area is 24.2661; thus, this is the service area with the shortest average time needed to reach all other service areas within the network. Areas B and C are located at Zunyi and Weng'an and are small areas with relatively high closeness. The closeness of the Xiazi, Zunyi, Weng'anxi, and Weng'andong service areas ranges between 17 and 20, indicating that the paths to other service areas and the average time taken are relatively short. Regions that are far away from Areas A, B, and C but have high kernel densities include the areas around Bijie City, Qianxi County, and Sansui County, where the closeness of the service areas varies from 15 to 20. The closeness of the Weining, Sanglang, and Libo service areas is less than 15, indicating that their geographical locations are relatively marginal, where the average path to other service areas and the average time taken are comparatively long. The Songtao, Liangcun, and Feigezi service areas have the lowest closeness level, ranging between 11 and 9 and, accordingly, are the most remote service areas for travel.

The high values of closeness in the Guizhou expressway transportation network are primarily distributed around Guiyang city, where the closeness levels are far higher than those of other regions. Thus, we can conclude that the route from Guiyang to all other service areas is the shortest and takes the least time on average, which indicates that Guiyang occupies a core position in the expressway transportation network of the entire Guizhou province.

3.1.3. Betweenness Centrality. Based on calculations using formula (3), we can see from Figure 4 and Table 3 that the betweenness of the Guizhou expressway transportation network varies from 0 to 35 . Its distribution shows a polycentric dispersed structure that is weakly concentric, where the overall layout is relatively concentrated, but the 
TABle 2: Closeness of expressway service areas in Guizhou province.

\begin{tabular}{|c|c|}
\hline Name & Closeness \\
\hline Longdongbao & 24.2661 \\
\hline Yunfeng & 23.3522 \\
\hline Yongle & 23.0056 \\
\hline Huoshipo & 22.7523 \\
\hline Huaxi & 22.7106 \\
\hline Baiyun & 22.1429 \\
\hline Kaiyang & 21.9858 \\
\hline Zhijindong & 21.9081 \\
\hline Guiding Tianfu & 21.7926 \\
\hline Huangping & 21.7544 \\
\hline Zhijin & 21.6405 \\
\hline Mouzhudong & 21.6405 \\
\hline Huishui & 21.6028 \\
\hline Qingyan & 21.4533 \\
\hline Longgang & 21.4162 \\
\hline Jiuchang & 21.3793 \\
\hline Maige & 21.3425 \\
\hline Longgong & 21.1244 \\
\hline Yangwu & 20.8754 \\
\hline Qianxi & 20.7705 \\
\hline Xifeng Wenquan & 20.7358 \\
\hline Dongtun & 20.5298 \\
\hline Majiang & 20.5298 \\
\hline Liuguanghe & 20.2946 \\
\hline Shangji Wujiang & 19.8400 \\
\hline Liutang & 19.6513 \\
\hline Wujiang & 19.5893 \\
\hline Qingshuijiang & 19.5893 \\
\hline Fuquan & 19.4969 \\
\hline Shangbao & 19.4662 \\
\hline Shuiyangwan & 19.2547 \\
\hline Yuqing & 19.2248 \\
\hline Lezhi & 19.1654 \\
\hline Xiazi & 19.1063 \\
\hline Weng'anxi & 19.0476 \\
\hline Changshun & 18.8450 \\
\hline Xingren & 18.7311 \\
\hline Sankeshu & 18.6747 \\
\hline Zunyi & 18.6186 \\
\hline Shibing & 18.6186 \\
\hline Yanjiao & 18.4799 \\
\hline Weng'annan & 18.4524 \\
\hline Haohuahong & 18.4250 \\
\hline Guanling & 18.3704 \\
\hline Ziyun & 18.1287 \\
\hline Weng'andong & 17.9971 \\
\hline Kanbian & 17.9191 \\
\hline Xixi & 17.8674 \\
\hline Jinsha & 17.8674 \\
\hline Dashaba & 17.6638 \\
\hline Renhuai & 17.5887 \\
\hline Tianxingqiao & 17.5637 \\
\hline Meitan & 17.5637 \\
\hline Jiudongtian & 17.3913 \\
\hline Weng'anbei & 17.3913 \\
\hline Hailong & 17.3184 \\
\hline Liupanshui & 17.2943 \\
\hline Yangchang & 17.2702 \\
\hline Huaqiao & 17.1034 \\
\hline Bijie Xinhua & 16.9399 \\
\hline Baiyangping & 16.7794 \\
\hline Hantun & 16.6443 \\
\hline
\end{tabular}

TABle 2: Continued.

\begin{tabular}{|c|c|}
\hline Name & Closeness \\
\hline Xiangshui & 16.6443 \\
\hline Xinzhai & 16.5997 \\
\hline Sinan & 16.5775 \\
\hline Baojing & 16.5554 \\
\hline Fuxing & 16.5333 \\
\hline Pingtang & 16.4238 \\
\hline Sansui & 16.4021 \\
\hline Kuanchang & 16.3804 \\
\hline Wenquan & 16.2516 \\
\hline Qinglong & 16.2304 \\
\hline Tongzi & 16.2092 \\
\hline Dewu & 16.1880 \\
\hline Zhenfeng & 16.0207 \\
\hline Dewang & 15.8771 \\
\hline Bianyang & 15.8568 \\
\hline Feilonghu & 15.8365 \\
\hline Meitandong & 15.7560 \\
\hline Longchangping & 15.5975 \\
\hline Wangmo & 15.5975 \\
\hline Shuijing & 15.5388 \\
\hline Jinyinshan & 15.5388 \\
\hline Tongren Xiangyang & 15.3276 \\
\hline Sige & 15.1961 \\
\hline Tuanjie & 15.1589 \\
\hline Faer & 15.1220 \\
\hline Sandong & 15.1220 \\
\hline Fuyang & 15.1035 \\
\hline Guanzhou & 15.0485 \\
\hline Weining & 14.8681 \\
\hline Sanglang & 14.6919 \\
\hline Libo & 14.6054 \\
\hline Chadian & 14.4860 \\
\hline Changerying & 14.3519 \\
\hline Liuguan & 14.3353 \\
\hline Jinping & 14.3187 \\
\hline Xihe & 14.0113 \\
\hline Hanlianhua & 13.9483 \\
\hline Yata & 13.8393 \\
\hline Tongren & 13.7168 \\
\hline Jichangping & 13.6414 \\
\hline Xinmin & 13.4490 \\
\hline Jiuqian & 13.3909 \\
\hline Yina & 13.3765 \\
\hline Zhengan & 13.3333 \\
\hline Zunyi Xiangyang & 13.2905 \\
\hline Danxia & 13.0115 \\
\hline Baotian & 12.9436 \\
\hline Hongguo & 12.8898 \\
\hline Daxiaojing & 12.8232 \\
\hline Anlong & 12.7835 \\
\hline Qiandongnan Xinhua & 12.7703 \\
\hline Wusha & 12.7049 \\
\hline Luoxiang & 12.1450 \\
\hline Panxin & 12.0976 \\
\hline Yueliangshan & 11.9923 \\
\hline Xishui & 11.7983 \\
\hline Wanglong & 11.7759 \\
\hline Daozhen & 11.7759 \\
\hline Liping & 11.6105 \\
\hline Zhaoxing & 11.0912 \\
\hline Songtao & 10.8014 \\
\hline Liangcun & 10.5802 \\
\hline Feigezi & 9.5753 \\
\hline
\end{tabular}


high-value areas are relatively scattered. Areas A, B, C, and $\mathrm{D}$ form the core areas of betweenness. Area A has the highest betweenness and is spatially located in the south of Guiyang city. In Area A, the betweenness of the Longdongbao service area is the highest at 34.8013, indicating that it is located on the greatest number of paths between pairs of service areas and is a "necessary path" for passenger flow between service areas. The betweenness of other service areas is also relatively high: for example, the betweenness of the Yunfeng, Yongle, and Guiding Tianfu service areas ranges between 10 and 20; thus, they occupy a core position. Areas B, C, and D are smaller areas concentrated around the Qianxi-ZhijinLonggong region, distributed along the Zunyi-Xiazi route, and centered on Huangping, respectively. Their betweenness levels range from 10 to 25 , forming smallscale "core-periphery" concentric structures. However, there are no transitional zones between these areas, and the betweenness drops to a low level in the intermediate areas-for example, that of the Maige service area is only 1.8884. This reflects the weak connectivity of the service areas in the intermediate concentric layers. As the Yina, Wanglong, Feigezi, and Tongzi service areas are not located between any node pairs, their betweenness is 0 , which indicates that they are located in the marginal regions of the expressways connecting Guizhou with the surrounding provinces.

The core region with respect to betweenness in the Guizhou expressway transportation network shows a clear trend of dispersion and is centered around Guiyang, Zhijin, Zunyi, and Huangping. The service areas in these regions occupy a core position and are connected to a relatively large number of other service areas. However, upon expanding the scope, we observe a sharp drop in the effective "intermediary" connective function of the service areas, with the formation of large, discontinuous intermediate regions.

3.1.4. Geographical Centrality. Based on calculations using formulas (4)-(7), the result of the Kaiser-Meyer-Olkin test is 0.715 and the Bartlett test significance value is 0.000 , which is below the significance level of 0.05 and is suitable for factor analysis. The weight coefficients calculated using factor analysis for degree, closeness, and betweenness are 0.388 , 0.394 , and 0.374, respectively. We can see from Figure 5 and Table 4 that the geographical centrality of the Guizhou expressway transportation network ranges from -1.28 to 3.33. Its distribution shows a single-core, polyconcentric dispersed spatial structure.

Area $\mathrm{A}$ is the core area of geographical centrality and is mainly concentrated in six municipal districts in the south of Guiyang city. Within this area, the geographical centrality of the Longdongbao, Yongle, and Guiding Tianfu service areas ranges between 1 and 3.33, while that of the Huaxi, Qingyan, Huoshipo, Baiyun, and Jiuchang service areas is all greater than 0 . These service areas have highly convenient transportation conditions and complete transportation infrastructure, enabling them to occupy the most central geographical location in the Guizhou expressway transportation network. Areas $\mathrm{B}$ and $\mathrm{C}$ are the central regions of geographical centrality. Area B is centered around the Yunfeng service area and includes the Longgong, Yangwu, Qianxi, and Zhijin service areas, with the geographic centrality ranging from 0.74 to 2.11 . However, a small low-value area is formed to the south of the Maige service area due to its lack of expressways in the north-south direction. Area $\mathrm{C}$ is centered around the Huangping service area, which has a geographical centrality of 2.0032, indicating that it has a high level of transportation convenience and accessibility. However, its long distance from Guiyang city resulted in its off-center position as a geographically central location. The geographical centrality of the transitional zones beyond Areas $\mathrm{B}$ and $\mathrm{C}$ ranges from 0 to 1 , indicating that these areas have slightly inadequate transportation convenience, accessibility, and intermediation but are not considered remote locations; they account for $39.20 \%$ of all service areas. Service areas with geographical centrality ranging between -0.7 and 0 account for $38.40 \%$ and are marginal regions in the network with an average geographical location for transportation. Service areas with a geographical centrality of less than -0.7 account for $16 \%$ of all areas and are located in the outlying areas of the overall transportation network. These areas include the Yueliangshan, Wanglong, Liangcun, Daozhen, Zhaoxing, Songtao, and Feigezi service areas, which have poor geographical locations for transportation.

The core region with respect to the geographical centrality of the Guizhou expressway transportation network is concentrated in the southern urban area of Guiyang city, where its geographical location has the greatest advantages of centrality-high connectivity, convenience, and accessibility. This is followed by the central region, which is mainly distributed in the periphery of the core region and spreads in the north-south and east-west directions along the main transport corridors; this region has a superior geographical location and infrastructure for transportation as well as high accessibility. The transitional zones are located in the periphery of the central region and have less adequate transportation convenience, accessibility, and intermediation compared to the central region. The marginal regions have average transportation connectivity, while the outlying regions have poor geographical locations for transportation.

\subsection{Distribution Characteristics of Passenger Flow Centrality.} Based on calculations using formulas (8) and (9), as shown in Table 5 and Figure 6, the passenger flow rate of all sections in the Guizhou expressway network ranges between 15,000 and 3.66 million. Its spatial layout primarily exhibits a dualcore, polycentric dispersed structure that is weakly concentric and relatively dispersed. Zunyi city (Area A) is the cluster region with the highest passenger flow rate in the Guizhou expressway transportation network. Here, the Zunyi service area has the highest passenger-car flow rate at 3.66 million followed by the Xiazi service area at 2.43 million. These service areas primarily receive tourists coming from Chongqing and 


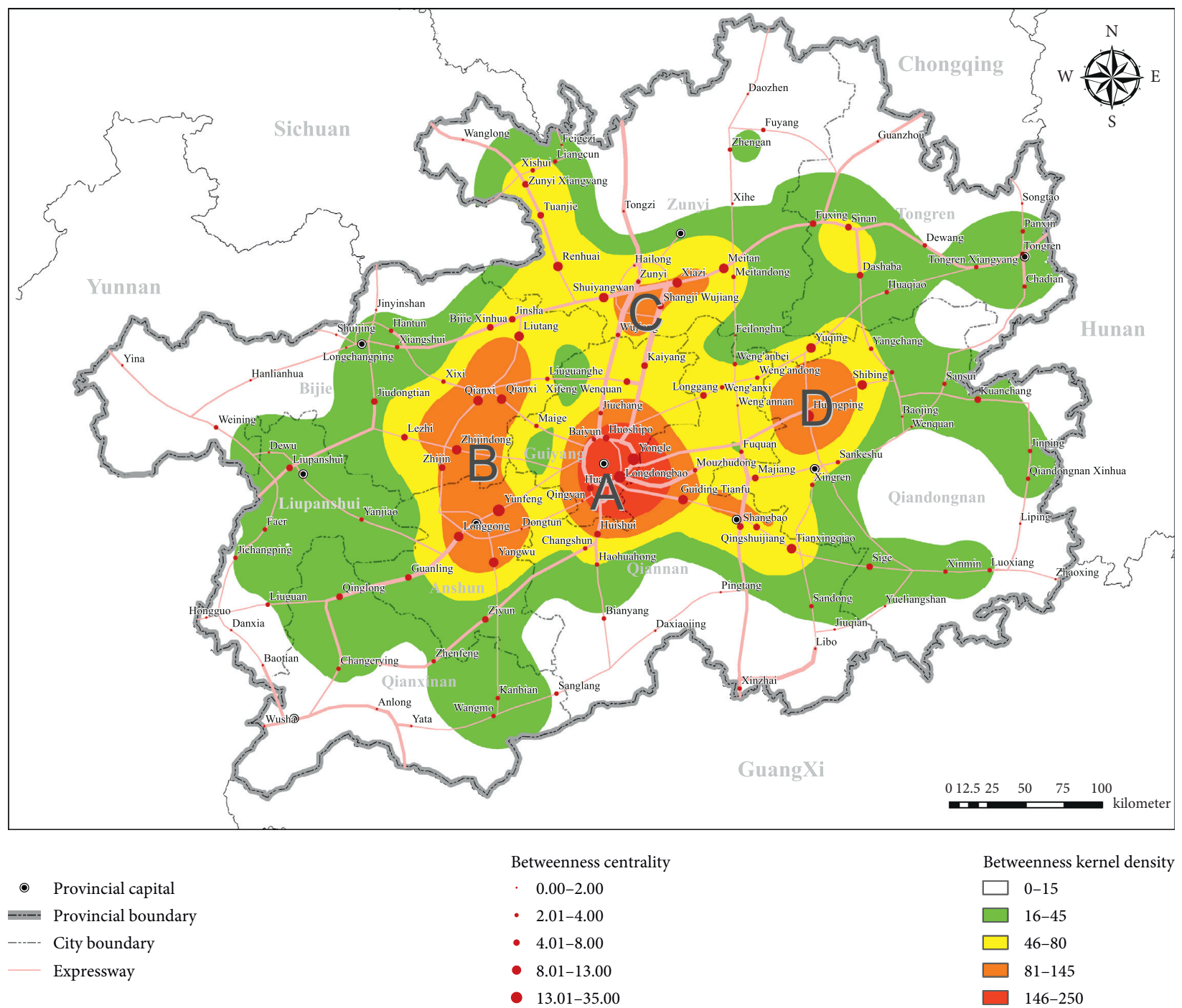

FIgURE 4: Kernel density plot of betweenness in the Guizhou expressway network.

Sichuan, forming the core region with the largest area with high flow rates. Guiyang city (Area B) attracts a large number of passenger-car transfers by virtue of its large population flow and convenient ring roads. Within this region, the passengercar flow rate of the Longdongbao service area is 2.37 million, which is second only to the Zunyi and Xiazi service areas and a core region with high flow rates. The two major core regions are connected to each other by north-south expressways. Among them, the Wujiang, Kaiyang, and Shangji Wujiang service areas that are closely connected to Zunyi city have an average passenger-car flow rate of around 1.82 million, whereas that of the Jiuchang, Yongle, Baiyun, and Huoshipo service areas around Longdongbao gradually decreases to 1.4 million.

The "polycenters" are primarily distributed in Guiding (Area C), Xingyi (Area D), Sinan (Area E), and Bijie (Area F). Among them, the Guiding Tianfu, Mouzhudong, Fuquan, and Majiang service areas in Guiding County have an average passenger-car flow rate of about 900,000, receiving passenger cars mostly from Guiyang city. The Wusha, Changerying, and Anlong service areas in Xingyi city experience an average passenger-car flow rate of about 600,000 and receive passenger cars mostly from Yunnan. The Sinan service area in Sinan County has a passenger-car flow rate of up to 1.12 million, primarily from merging passenger cars from Hunan and Chongqing. The Longchangping and Xiangshui service areas in Bijie city experience an average passenger-car flow rate of 540,000, and they generally receive passenger cars from Yunnan and Sichuan.

The average passenger-car flow rate of median-value regions is about 650,000 , which follows a zonal distribution along the expressway transport corridors. These regions are concentrated along the peripheries of the Lanhai, Hangrui, Hukun, and Shankun expressways. Other service areas beyond the regions above, such as the Daozhen, Yina, Xinmin, and Daxiaojing service areas, have an average passenger-car flow rate of about 100,000 . In particular, areas such as southeast Qiandongnan, southwest Qiannan, southeast Qianxinan, northwest Bijie, and north Zunyi have low passenger-car flow rates, thus constituting the marginal regions. 
TABle 3: Betweenness of expressway service areas in Guizhou province.

\begin{tabular}{|c|c|}
\hline Name & Betweenness \\
\hline Longdongbao & 34.8013 \\
\hline Huangping & 22.3045 \\
\hline Yunfeng & 20.1288 \\
\hline Yongle & 18.6511 \\
\hline Guiding Tianfu & 13.1280 \\
\hline Qianxi & 11.7287 \\
\hline Shuiyangwan & 11.3840 \\
\hline Longgong & 11.3290 \\
\hline Xiazi & 10.8608 \\
\hline Zhijindong & 10.6430 \\
\hline Yuqing & 10.5387 \\
\hline Tianxingqiao & 9.4155 \\
\hline Meitan & 9.3063 \\
\hline Renhuai & 9.2840 \\
\hline Shibing & 8.8271 \\
\hline Yangwu & 8.8057 \\
\hline Liutang & 8.5227 \\
\hline Tuanjie & 7.8023 \\
\hline Lezhi & 7.6282 \\
\hline Huishui & 7.4428 \\
\hline Kaiyang & 7.2087 \\
\hline Qingshuijiang & 7.0535 \\
\hline Liupanshui & 6.9696 \\
\hline Longgang & 6.8019 \\
\hline Guanling & 6.6514 \\
\hline Sinan & 6.2995 \\
\hline Zunyi Xiangyang & 6.2943 \\
\hline Zhijin & 5.9361 \\
\hline Dashaba & 5.8976 \\
\hline Qinglong & 5.8694 \\
\hline Fuxing & 5.6472 \\
\hline Huaxi & 5.5953 \\
\hline Majiang & 5.5557 \\
\hline Jiudongtian & 5.3775 \\
\hline Huoshipo & 5.0972 \\
\hline Shangbao & 5.0533 \\
\hline Shangji Wujiang & 4.8513 \\
\hline Ziyun & 4.8175 \\
\hline Sige & 4.8009 \\
\hline Xifeng Wenquan & 4.7644 \\
\hline Jinsha & 4.6453 \\
\hline Kuanchang & 4.6282 \\
\hline Bijie Xinhua & 4.3175 \\
\hline Kanbian & 4.0857 \\
\hline Yanjiao & 4.0442 \\
\hline Baiyun & 3.8784 \\
\hline Changerying & 3.8274 \\
\hline Xinmin & 3.7398 \\
\hline Wujiang & 3.5778 \\
\hline Tongren & 3.5464 \\
\hline Xingren & 3.5093 \\
\hline Sansui & 3.4839 \\
\hline Haohuahong & 3.3451 \\
\hline Zhenfeng & 3.3341 \\
\hline Jinping & 3.2033 \\
\hline Xishui & 3.1996 \\
\hline Wangmo & 3.1000 \\
\hline Tongren Xiangyang & 3.0211 \\
\hline Weng'anxi & 3.0122 \\
\hline Mouzhudong & 2.9682 \\
\hline Meitandong & 2.9068 \\
\hline Sankeshu & 2.8848 \\
\hline
\end{tabular}

TABle 3: Continued.

\begin{tabular}{|c|c|}
\hline Name & Betweenness \\
\hline Faer & 2.7247 \\
\hline Xixi & 2.7239 \\
\hline Huaqiao & 2.6556 \\
\hline Jiuchang & 2.4818 \\
\hline Liuguanghe & 2.4729 \\
\hline Fuyang & 2.4458 \\
\hline Liuguan & 2.2368 \\
\hline Changshun & 2.1933 \\
\hline Hantun & 2.1835 \\
\hline Xiangshui & 2.1835 \\
\hline Xinzhai & 2.1815 \\
\hline Weng'anbei & 2.1618 \\
\hline Chadian & 2.0497 \\
\hline Fuquan & 2.0174 \\
\hline Zhengan & 1.9616 \\
\hline Bianyang & 1.9473 \\
\hline Weining & 1.9296 \\
\hline Yangchang & 1.9258 \\
\hline Luoxiang & 1.8949 \\
\hline Maige & 1.8884 \\
\hline Qiandongnan Xinhua & 1.8308 \\
\hline Baiyangping & 1.7890 \\
\hline Sanglang & 1.7886 \\
\hline Sandong & 1.7691 \\
\hline Weng'andong & 1.7586 \\
\hline Dewang & 1.7172 \\
\hline Jichangping & 1.6521 \\
\hline Liangcun & 1.6129 \\
\hline Panxin & 1.6129 \\
\hline Zunyi & 1.6079 \\
\hline Weng'annan & 1.4250 \\
\hline Longchangping & 1.4026 \\
\hline Feilonghu & 1.1876 \\
\hline Dewu & 1.1677 \\
\hline Jiuqian & 1.1269 \\
\hline Xihe & 1.0631 \\
\hline Libo & 1.0068 \\
\hline Liping & 0.8896 \\
\hline Yata & 0.7684 \\
\hline Danxia & 0.7096 \\
\hline Baotian & 0.6217 \\
\hline Hanlianhua & 0.6210 \\
\hline Anlong & 0.5825 \\
\hline Baojing & 0.5414 \\
\hline Qingyan & 0.4819 \\
\hline Dongtun & 0.3863 \\
\hline Wenquan & 0.3309 \\
\hline Yueliangshan & 0.2732 \\
\hline Hailong & 0.1672 \\
\hline Yina & 0.0000 \\
\hline Shuijing & 0.0000 \\
\hline Jinyinshan & 0.0000 \\
\hline Wanglong & 0.0000 \\
\hline Feigezi & 0.0000 \\
\hline Tongzi & 0.0000 \\
\hline Hongguo & 0.0000 \\
\hline Wusha & 0.0000 \\
\hline Daxiaojing & 0.0000 \\
\hline Pingtang & 0.0000 \\
\hline Zhaoxing & 0.0000 \\
\hline Daozhen & 0.0000 \\
\hline Guanzhou & 0.0000 \\
\hline Songtao & 0.0000 \\
\hline
\end{tabular}




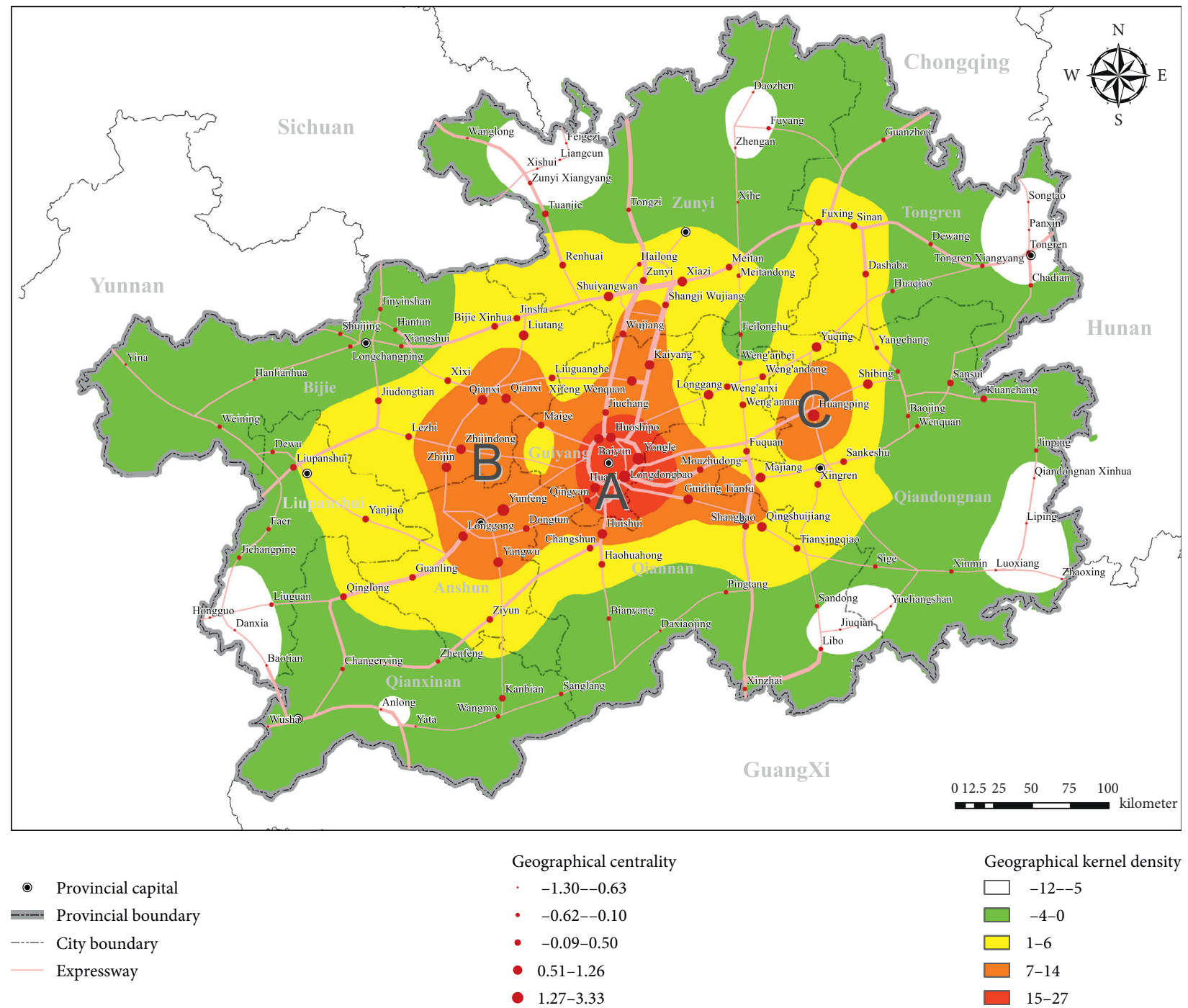

FIGURE 5: Kernel density plot of geographical centrality in the Guizhou expressway network.

The spatial distribution of passenger-car flow rates in the Guizhou expressway network is characterized by Zunyi city and Guiyang city as its dual-core, Guiding, Xingyi, Sinan, and Bijie as its secondary centers, and distribution along its transport corridors. However, the low passenger-car flow rates in the margins of the province are also highly significant.

\subsection{Analysis of Tourism Utilization Potential of Expressway} Service Areas. After calculations using formulas (10) and (11), based on the geographical centrality and passenger flow centrality, a coordinate plot for 125 geographical-passenger flow centrality pairs was created (Figure 7). As shown in Figure 8 , there is a positive spatial correlation between the distribution of the geographical centrality and passenger flow centrality of expressway service areas. The bivariate global autocorrelation coefficient is 0.22 , which indicates that expressway service areas tend to be built in areas with high passenger flow to a certain extent, thus providing transportation service facilities with high accessibility. Furthermore, the more complete the development of transportation conditions, the greater the passenger flow these areas will attract. To test whether Moran's I was significant, a Monte Carlo simulation was used in GeoDa. The $P$ value was equal to 0.001 , indicating that spatial autocorrelation is significant at $99.9 \%$ confidence interval.

The passenger-car flow rate is indicative of the potential tourist flow rate, and the accessibility of the transportation network will affect tourists' travel willingness and behaviors. Therefore, in Moran's I scatter plot, values along the geographical centrality $y$-axis $>1,>0$ and $<1,>-1$ and $<0$, and $<-1$ are defined as high, moderately high, moderately low, and low geographical centrality, respectively; values along the passenger flow centrality $x$-axis $>0$ and $<0$ are defined as high and low passenger flow centrality, respectively. As the difference between "low geographical centrality-low passenger flow centrality" and "moderately low geographical centrality-low passenger flow centrality" was of limited practical significance, these were merged into "low 
TABLE 4: Geographical centrality of expressway service areas in Guizhou province.

\begin{tabular}{|c|c|}
\hline Name & Geographical centrality \\
\hline Longdongbao & 3.3296 \\
\hline Yunfeng & 2.1029 \\
\hline Huangping & 2.0033 \\
\hline Yongle & 1.8517 \\
\hline Guiding Tianfu & 1.2610 \\
\hline Zhijindong & 1.1585 \\
\hline Longgong & 1.0921 \\
\hline Qianxi & 1.0799 \\
\hline Shuiyangwan & 0.8953 \\
\hline Huaxi & 0.8710 \\
\hline Yangwu & 0.8700 \\
\hline Kaiyang & 0.8338 \\
\hline Huishui & 0.8297 \\
\hline Xiazi & 0.8133 \\
\hline Huoshipo & 0.7897 \\
\hline Yuqing & 0.7788 \\
\hline Longgang & 0.7584 \\
\hline Zhijin & 0.7438 \\
\hline Liutang & 0.6768 \\
\hline Baiyun & 0.6478 \\
\hline Majiang & 0.6296 \\
\hline Shibing & 0.5756 \\
\hline Qingshuijiang & 0.5333 \\
\hline Xifeng Wenquan & 0.5214 \\
\hline Lezhi & 0.5017 \\
\hline Mouzhudong & 0.4695 \\
\hline Tianxingqiao & 0.4690 \\
\hline Renhuai & 0.4620 \\
\hline Meitan & 0.4364 \\
\hline Jiuchang & 0.4010 \\
\hline Shangbao & 0.3905 \\
\hline Maige & 0.3756 \\
\hline Shangji Wujiang & 0.3716 \\
\hline Guanling & 0.3316 \\
\hline Liupanshui & 0.2989 \\
\hline Wujiang & 0.2687 \\
\hline Qingyan & 0.2577 \\
\hline Liuguanghe & 0.2454 \\
\hline Dashaba & 0.2376 \\
\hline Jiudongtian & 0.2137 \\
\hline Ziyun & 0.1871 \\
\hline Yanjiao & 0.1706 \\
\hline Dongtun & 0.1634 \\
\hline Weng'anxi & 0.1604 \\
\hline Xingren & 0.1602 \\
\hline Jinsha & 0.1426 \\
\hline Sinan & 0.1373 \\
\hline Sankeshu & 0.1301 \\
\hline Fuquan & 0.1146 \\
\hline Haohuahong & 0.0865 \\
\hline Kanbian & 0.0819 \\
\hline Fuxing & 0.0581 \\
\hline Zunyi & 0.0504 \\
\hline Changshun & 0.0495 \\
\hline Qinglong & 0.0385 \\
\hline Tuanjie & 0.0080 \\
\hline Bijie Xinhua & 0.0059 \\
\hline Xixi & -0.0037 \\
\hline Weng'annan & -0.0321 \\
\hline
\end{tabular}

TABle 4: Continued.

\begin{tabular}{|c|c|}
\hline Name & Geographical centrality \\
\hline Kuanchang & -0.0379 \\
\hline Weng'andong & -0.0615 \\
\hline Sansui & -0.0739 \\
\hline Huaqiao & -0.1009 \\
\hline Weng'anbei & -0.1038 \\
\hline Xiangshui & -0.1194 \\
\hline Hantun & -0.1194 \\
\hline Yangchang & -0.1364 \\
\hline Baiyangping & -0.1816 \\
\hline Zhenfeng & -0.2039 \\
\hline Sige & -0.2159 \\
\hline Xinzhai & -0.2219 \\
\hline Hailong & -0.2644 \\
\hline Meitandong & -0.2684 \\
\hline Wangmo & -0.2727 \\
\hline Baojing & -0.3036 \\
\hline Zunyi Xiangyang & -0.3076 \\
\hline Tongren Xiangyang & -0.3113 \\
\hline Changerying & -0.3189 \\
\hline Dewu & -0.3244 \\
\hline Longchangping & -0.3292 \\
\hline Dewang & -0.3443 \\
\hline Bianyang & -0.3535 \\
\hline Fuyang & -0.3578 \\
\hline Faer & -0.3586 \\
\hline Wenquan & -0.4047 \\
\hline Feilonghu & -0.4137 \\
\hline Weining & -0.4254 \\
\hline Sandong & -0.4313 \\
\hline Pingtang & -0.4334 \\
\hline Tongzi & -0.4350 \\
\hline Jinping & -0.4432 \\
\hline Tongren & -0.4653 \\
\hline Liuguan & -0.4662 \\
\hline Shuijing & -0.4672 \\
\hline Jinyinshan & -0.4672 \\
\hline Sanglang & -0.4816 \\
\hline Xinmin & -0.4829 \\
\hline Chadian & -0.5108 \\
\hline Libo & -0.5516 \\
\hline Guanzhou & -0.5748 \\
\hline Jichangping & -0.5943 \\
\hline Zhengan & -0.6321 \\
\hline Xihe & -0.6431 \\
\hline Hanlianhua & -0.6601 \\
\hline Yata & -0.6862 \\
\hline Jiuqian & -0.6887 \\
\hline Xishui & -0.7228 \\
\hline Qiandongnan Xinhua & -0.7342 \\
\hline Danxia & -0.7419 \\
\hline Baotian & -0.7568 \\
\hline Anlong & -0.7791 \\
\hline Luoxiang & -0.7804 \\
\hline Yina & -0.8005 \\
\hline Panxin & -0.8318 \\
\hline Hongguo & -0.8349 \\
\hline Wusha & -0.8571 \\
\hline Daxiaojing & -0.8914 \\
\hline Liping & -0.9213 \\
\hline Yueliangshan & -0.9464 \\
\hline
\end{tabular}


TABle 4: Continued.

\begin{tabular}{lc}
\hline Name & Geographical centrality \\
\hline Wanglong & -0.9933 \\
Liangcun & -1.0146 \\
Daozhen & -1.0175 \\
Zhaoxing & -1.0758 \\
Songtao & -1.1349 \\
Feigezi & -1.2826 \\
\hline
\end{tabular}

geographical centrality-low passenger flow centrality" for the analysis. This produced seven major categories, as shown in Table 6.

3.3.1. High-High Cluster. Service areas in the "high-high" cluster type are geographically located at the center of the expressway transportation network. These service areas have complete expressway transportation facilities, high transportation convenience, accessibility, and intermediation, as well as a high number of core scenic areas and large passenger-car flow rate. This type of the service area is generally distributed around Guiyang city, as well as in Anshun (Longgong), Bijie (Jinsha and Qianxi), Qiannan (Guiding Tianfu, Mouzhudong, and Fuquan), and Qiandongnan (Majiang). They account for $13.6 \%$ of all service areas, with an average geographical centrality of about 0.90 and an average passenger-car flow rate of up to 1.17 million. Service areas in the "high-high" cluster type have the greatest potential for tourism utilization and can rely on major transportation hubs and passenger-car flow rates to enhance the focus of the transportation hub-type service areas.

3.3.2. Moderately High-High Cluster. Service areas in the "moderately high-high" cluster type are supported by highquality scenic areas and large passenger flow, but their geographical locations are not sufficiently central, and they do not have adequate transportation convenience, accessibility, and intermediation. Hence, the geographical centrality of these service areas is slightly lower than that of the "high-high" cluster type. These service areas are mainly distributed in Zunyi, as well as Bijie (Xiangshui and Jiudongtian), Anshun (Guanling and Ziyun), Qiannan (Shangbao), and Qiandongnan (Huangping). They account for $9.6 \%$ of all service areas, with an average geographical centrality of about 0.44 and an average passenger-car flow rate of up to 1.26 million, far exceeding those of the "high-high" cluster type. The rapid development of red tourism in such service areas, including Zunyi, has resulted in large passenger flows from Chongqing, Sichuan, and Hunan. Their potential for tourism utilization is also high, and these regions can rely on the concentrated transfer of large passenger flows. Therefore, the construction of service areas relying on tourist attraction can be improved.

3.3.3. Low-High Cluster. Service areas in the "low-high" cluster type have extremely marginal geographical locations.
TABle 5: Passenger-car flow rates of expressway service areas in Guizhou province.

\begin{tabular}{|c|c|}
\hline Name & Flow \\
\hline Zunyi & $3,661,081$ \\
\hline Xiazi & $2,431,688$ \\
\hline Longdongbao & $2,369,429$ \\
\hline Wujiang & $1,892,692$ \\
\hline Kaiyang & $1,791,420$ \\
\hline Shangji Wujiang & $1,790,814$ \\
\hline Jiuchang & $1,692,232$ \\
\hline Yongle & $1,473,084$ \\
\hline Baiyun & $1,362,797$ \\
\hline Majiang & $1,283,252$ \\
\hline Hailong & $1,143,308$ \\
\hline Sinan & $1,118,963$ \\
\hline Qinglong & $1,085,028$ \\
\hline Huoshipo & $1,075,324$ \\
\hline Longgong & $1,065,735$ \\
\hline Fuquan & $1,022,454$ \\
\hline Shuiyangwan & 986,808 \\
\hline Guanling & 962,574 \\
\hline Huishui & 901,144 \\
\hline Liupanshui & 869,839 \\
\hline Shangbao & 825,564 \\
\hline Mouzhudong & 791,746 \\
\hline Huangping & 789,166 \\
\hline Xinzhai & 763,012 \\
\hline Jiudongtian & 728,219 \\
\hline Renhuai & 702,210 \\
\hline Qianxi & 701,471 \\
\hline Tongren & 685,608 \\
\hline Wusha & 668,470 \\
\hline Anlong & 637,520 \\
\hline Zhenfeng & 606,424 \\
\hline Xifeng Wenquan & 601,833 \\
\hline Xiangshui & 592,971 \\
\hline Fuxing & 587,794 \\
\hline Jinsha & 585,045 \\
\hline Dewang & 578,103 \\
\hline Guiding Tianfu & 555,510 \\
\hline Tuanjie & 546,301 \\
\hline Tongren Xiangyang & 543,816 \\
\hline Zunyi Xiangyang & 517,868 \\
\hline Ziyun & 511,282 \\
\hline Longchangping & 494,850 \\
\hline Changshun & 483,479 \\
\hline Changerying & 480,507 \\
\hline Yuqing & 471,780 \\
\hline Bijie Xinhua & 462,451 \\
\hline Tongzi & 443,813 \\
\hline Meitan & 437,170 \\
\hline Sankeshu & 423,887 \\
\hline Dashaba & 418,023 \\
\hline Libo & 413,940 \\
\hline Zhijindong & 403,976 \\
\hline Yata & 379,674 \\
\hline Hanlianhua & 362,812 \\
\hline Haohuahong & 347,559 \\
\hline Maige & 331,908 \\
\hline Chadian & 322,606 \\
\hline Yanjiao & 312,802 \\
\hline Zhijin & 309,954 \\
\hline
\end{tabular}


TABle 5: Continued.

\begin{tabular}{|c|c|}
\hline Name & Flow \\
\hline Jinyinshan & 302,366 \\
\hline Liping & 297,774 \\
\hline Baotian & 287,978 \\
\hline Weng'annan & 287,713 \\
\hline Xingren & 285,228 \\
\hline Yangchang & 272,377 \\
\hline Liutang & 270,751 \\
\hline Wanglong & 268,958 \\
\hline Guanzhou & 268,172 \\
\hline Lezhi & 256,067 \\
\hline Sansui & 253,625 \\
\hline Weng'andong & 253,225 \\
\hline Liuguanghe & 252,862 \\
\hline Panxin & 251,448 \\
\hline Baojing & 249,026 \\
\hline Qiandongnan Xinhua & 237,566 \\
\hline Faer & 235,737 \\
\hline Huaqiao & 231,525 \\
\hline Baiyangping & 226,532 \\
\hline Yunfeng & 222,684 \\
\hline Liuguan & 218,770 \\
\hline Bianyang & 208,504 \\
\hline Dongtun & 203,993 \\
\hline Yangwu & 201,454 \\
\hline Huaxi & 196,867 \\
\hline Shuijing & 194,059 \\
\hline Weining & 186,973 \\
\hline Jichangping & 178,594 \\
\hline Kuanchang & 177,358 \\
\hline Jinping & 177,358 \\
\hline Hantun & 177,178 \\
\hline Danxia & 167,605 \\
\hline Luoxiang & 164,756 \\
\hline Meitandong & 161,945 \\
\hline Wenquan & 154,567 \\
\hline Xixi & 150,893 \\
\hline Weng'anxi & 141,313 \\
\hline Tianxingqiao & 125,982 \\
\hline Weng'anbei & 125,768 \\
\hline Qingyan & 124,219 \\
\hline Qingshuijiang & 112,417 \\
\hline Wangmo & 109,460 \\
\hline Shibing & 108,028 \\
\hline Sanglang & 100,589 \\
\hline Dewu & 96,270 \\
\hline Yina & 90,703 \\
\hline Fuyang & 87,313 \\
\hline Feilonghu & 80,973 \\
\hline Xishui & 80,198 \\
\hline Liangcun & 80,198 \\
\hline Zhaoxing & 74,444 \\
\hline Longgang & 67,238 \\
\hline Songtao & 66,075 \\
\hline Daxiaojing & 61,475 \\
\hline Xinmin & 58,972 \\
\hline Zhengan & 54,161 \\
\hline Xihe & 53,562 \\
\hline Sige & 49,865 \\
\hline Hongguo & 49,457 \\
\hline Pingtang & 45,500 \\
\hline
\end{tabular}

TABLE 5: Continued.

\begin{tabular}{lc}
\hline Name & Flow \\
\hline Yueliangshan & 43,302 \\
Kanbian & 40,921 \\
Feigezi & 40,099 \\
Sandong & 35,431 \\
Jiuqian & 28,868 \\
Daozhen & 14,934 \\
\hline
\end{tabular}

They are typically distributed at the intersections between Guizhou and other provinces but have high passenger-car flow rates. For example, the Tongren, Xiangyang, Tuanjie, Wusha, and Xinzhai service areas account for $4.8 \%$ of all service areas and have an average geographical centrality of about -0.36 , but their average passenger-car flow rate is 620,000 . Although such service areas are not the core nodes in terms of geographical location, they are situated at crucial gateway positions in Guizhou province, receiving a large volume of tourists from other provinces. These areas have great potential for tourism utilization and development and can serve as "image windows" for external publicity. Therefore, they can be improved by the construction of tourism gateway-type service areas.

3.3.4. Moderately Low-High Cluster. Service areas in the "moderately low-high" cluster type are similar to those in the "low-high" cluster type in that they have high passenger flow but are located at relatively marginal areas in the overall network. For example, the Tongren area (Dewang, Sinan, and Fuxing) receives tourists coming from Dewang and Xiangyang; the Bijie area (Longchangping) receives tourists coming from northwestern Yunnan; and Qianxinan (Anlong, Qinglong, and Zhenfeng) receives Yunnan tourists coming from Wusha. These service areas account for $6.4 \%$, with an average geographical centrality of about -0.14 and an average passenger-car flow rate of 750,000. These types of service areas are located at internal connections with "lowhigh" service areas and function as secondary gateways for Guizhou province. They can be upgraded through the construction of secondary gateway-type service areas.

3.3.5. High-Low Cluster. Service areas in the "high-low" cluster type have low passenger flow but are geographically situated at core nodes in the overall transportation network. They are generally distributed in the west of Guiyang city, northeast of Anshun city, west of Bijie, north of Qiannan, and west of Qiandongnan. These service areas account for $16.8 \%$, with an average geographical centrality of about 0.41 and an average passenger-car flow rate of 240,000. This type of service area, such as Huaxi and Qingyan, experiences a high level of infrastructure construction but an extremely low passenger flow due to insufficient attractiveness. However, given their proximity to city suburbs and the leisure needs of large urban populations, they can be improved via the construction of urban leisure-type service areas. 


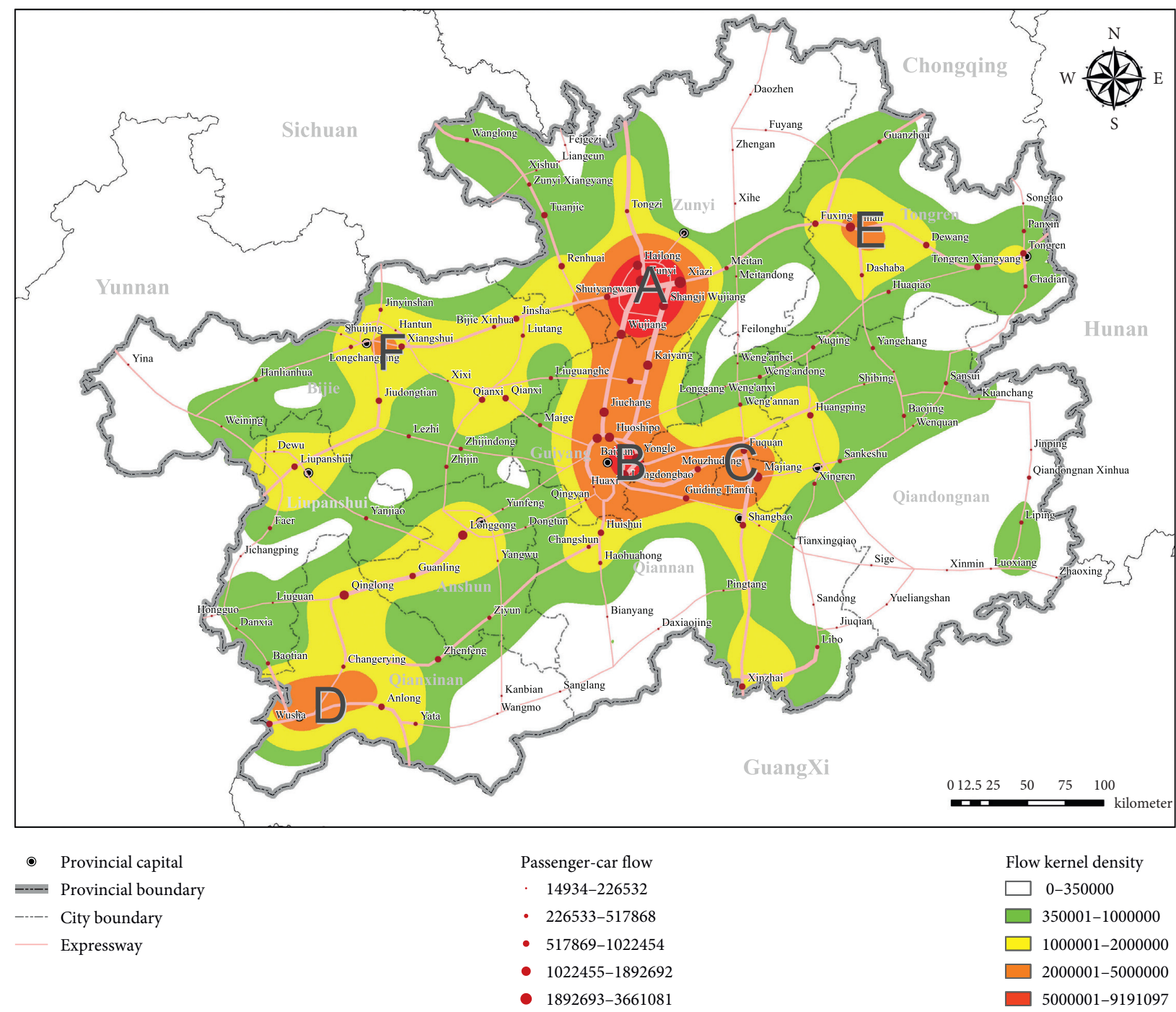

FIGURE 6: Kernel density plot of passenger-car flow rates in the Guizhou expressway network.

3.3.6. Moderately High-Low Cluster. Service areas in the "moderately high-low" cluster type have low passenger flows and insufficiently central geographical locations. They are mostly distributed in northwestern Qiandongnan, as well as Qiannan (Qingshuijiang and Pingtang), Tongren (Huaqian), Zunyi (Meitandong and Yuqing), Bijie (Xinhua), and Liupanshui (Yanjiao). These service areas account for $10.4 \%$, with an average geographical centrality of about 0.03 and an average passenger-car flow rate of 240,000. They are situated neither on the periphery of cities nor at the intersections between provincial borders. To improve, they can be linked with the surrounding villages through the construction of rural leisure-type service areas.

3.3.7. Low-Low Cluster. Service areas in the "low-low" cluster type have extremely low passenger flows and are located in the marginal zones, which are distributed in the northwest of Bijie, north of Zunyi, west of Liupanshui, southeast of Qianxinan, south of Qiannan, northwest of Qiandongnan, and west of Tongren. These service areas account for $39.2 \%$, with an average geographical centrality of about -0.54 and an average passenger-car flow rate of 170,000 , indicating their low tourism utilization potential. In such service areas, the construction of comprehensive community service centers and agricultural product trade show centers can be undertaken to develop and upgrade them as community co-construction and sharing-type service areas.

\section{Conclusions and Discussion}

4.1. Conclusions. This study performed a comprehensive analysis of the complexity of the expressway transportation network in Guizhou province, which enabled us to understand the differences between its geographical 


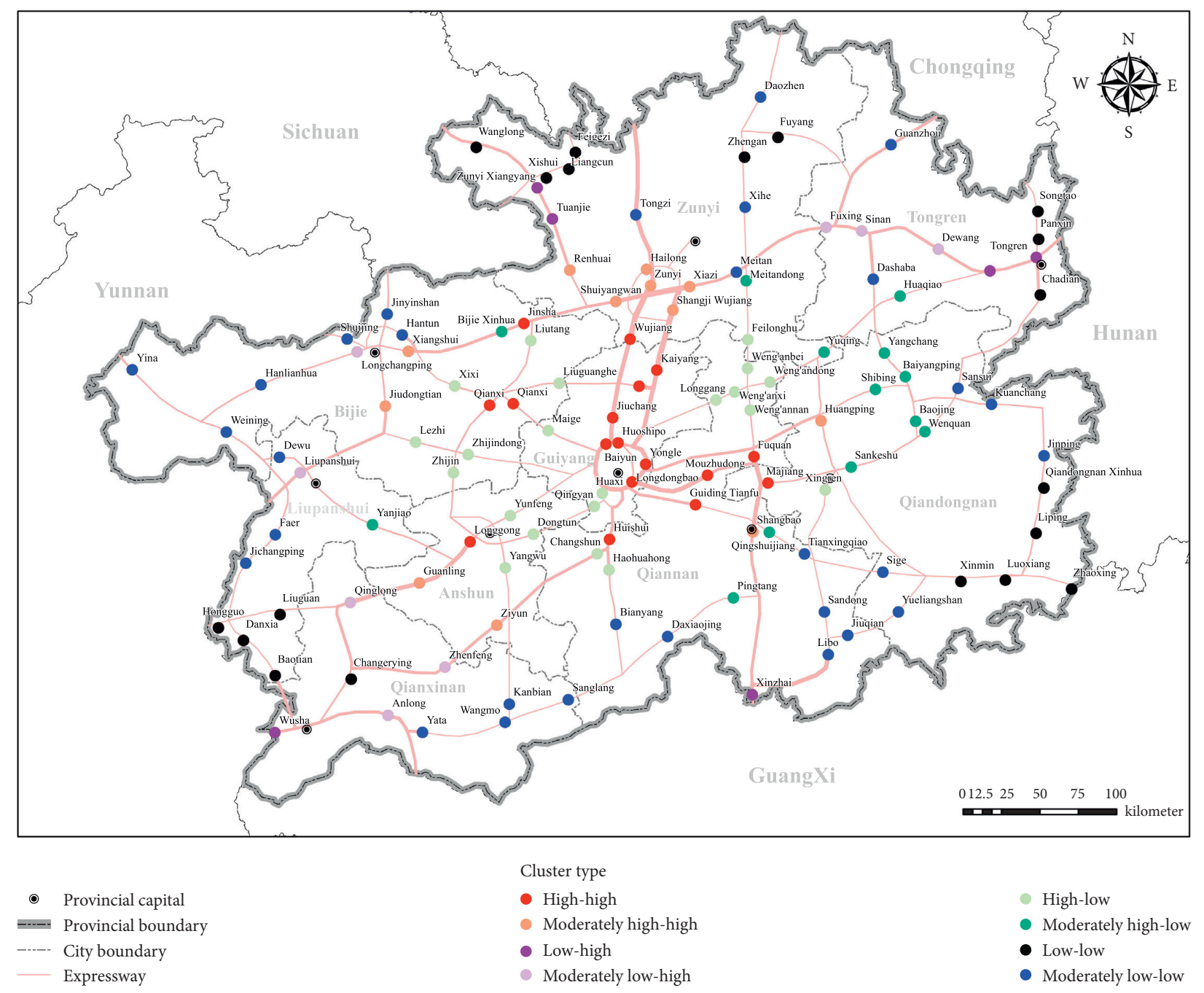

Figure 7: Distribution of the bivariate local cluster of expressway service areas in Guizhou province.

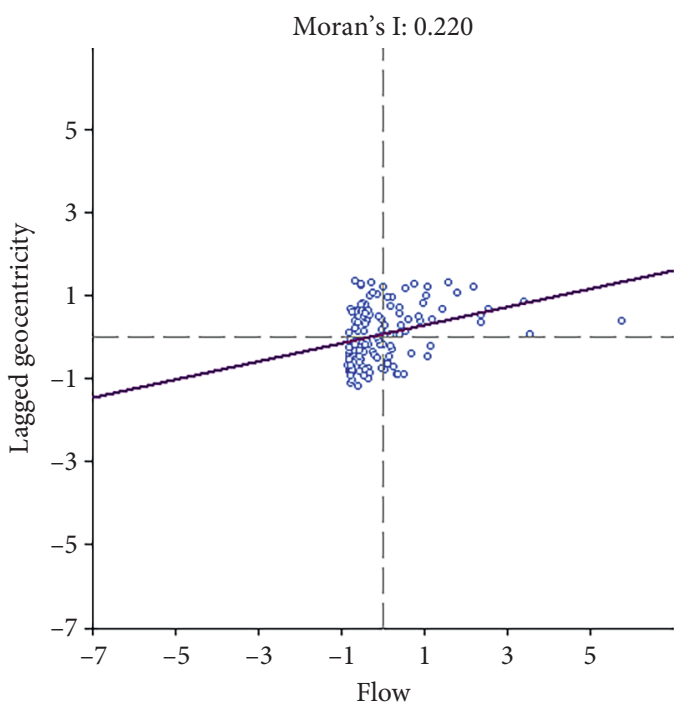

(a)

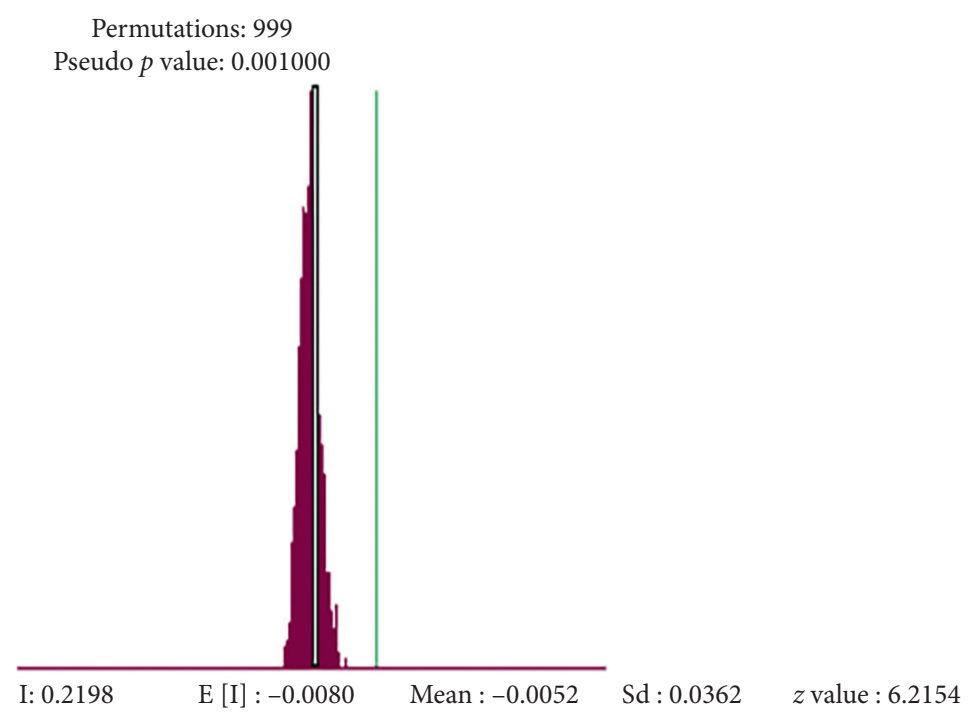

(b)

Figure 8: Moran's I scatter plot and test plot. 
TABLE 6: Cluster types of geographical centrality-passenger flow centrality and tourism development models of expressway service areas in Guizhou province.

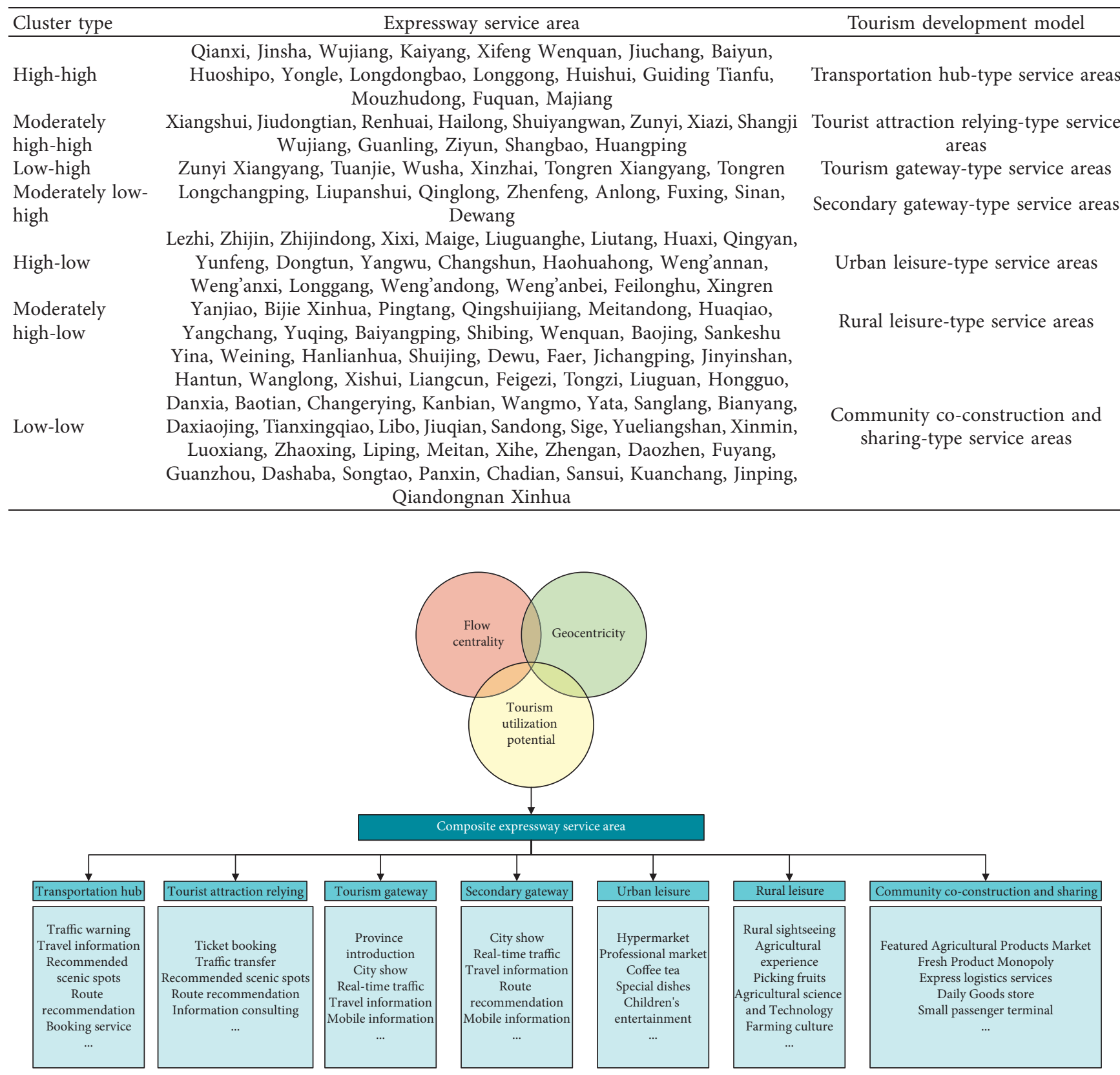

FIGURE 9: Seven types of development models for expressway service areas.

advantage and actual passenger flow advantage and allowed us to explore the tourism utilization potential of expressway service areas. Our main conclusions are as follows:

(1) The geographical centrality of the Guizhou expressway transportation network generally ranges between -1.28 and 3.33 , and its distribution shows a single-core polyconcentric dispersed spatial structure. The core region is located in the south of Guiyang city, where the geographical centrality is concentrated between 1 and 3.33, and the area had the greatest advantage with respect to centrality. The central regions are distributed in Anshun and Bijie, where the geographical centrality is concentrated between 0.72 and 2.11 , and the areas had superior transportation conditions and infrastructure. Other areas are located in the marginal zones of Guizhou province, where the geographical centrality is less than 0 , and transportation conditions are poor.

(2) The passenger-car flow rate of the Guizhou expressway transportation network mainly ranges 
between 15,000 and 3.66 million, and its distribution shows a dual-core, polycentric dispersed structure that is weakly concentric. Zunyi and Guiyang are the dual cores of the passenger flow network, with passenger-car flow rates of up to 2.37-3.66 million. Guiding, Xingyi, Sinan, and Bijie are the secondary centers, with an average passenger-car flow rate of about 800,000 . The median-value regions had an average passenger-car flow rate of about 650,000, while the marginal regions had an average passenger-car flow rate of about 10,000.

(3) On the whole, the geographical centrality indicator and passenger flow indicator of the Guizhou expressway transportation network show a positive correlation of 0.22 . This implies that expressway service areas tend to be constructed in areas with dense passenger flows, and core geographical locations have greater passenger flows. Based on the differences between the geographical advantage and actual passenger flow advantage in the expressway transportation network, the tourism utilization potential of the expressway service areas could be divided into seven types. Service areas in the "high-high" cluster type around Guiyang city should focus on their future development as transportation hub-type service areas, while those in the "moderately high-high" cluster type near Zunyi city should focus on their development as service areas relying on tourist attraction. Service areas in the "moderately lowhigh" and "low-high" cluster types should develop themselves as tourism gateways. Service areas in the "high-low" cluster type around Guiyang city should be developed as urban leisure-type service areas, while "moderately high-low" cluster-type areas should develop their rural leisure-type services. Finally, service areas in the "low-low" cluster type should design their development as community co-construction and sharing-type service areas.

4.2. Discussion. Expressways are an important part of the complex transportation network system. Due to the different geographic locations and passenger-car flow conditions of each node in an expressway network, the functions undertaken in the complex transportation network system are different, forming a complex network relationship with different divisions of labor. The complexity of expressway transportation networks is mainly reflected in the following three aspects: (1) the complexity of connectivity elements-expressways connect a variety of spatial elements such as cities, villages, and attractions; (2) the complexity of network structures, mainly including traffic connectivity, accessibility, intermediation, and other spatial complexity features; (3) the complexity of actual passenger flow-passenger flow trends will lead to expressway transportation network nodes having specific functions, increasing the complexity of expressway transportation networks.

Studies have been conducted to analyze the spatial structure characteristics of complex networks such as railways, airlines, and urban transportation using indicators such as degree centrality, closeness centrality, and betweenness centrality and to delineate the hierarchical structure and group structure of node centrality in transportation network systems [59]. In this study, from the less researched expressway perspective, the complex spatial features of the expressway transportation network were innovatively subsumed into two indicators of geographical centrality and passenger flow centrality, and coupled clustering was used to quantitatively analyze the difference between the geographic advantage and passenger flow advantage of the expressway transportation network. The study found that the most geographically advantaged nodes of the transportation network are often located at the center of the entire network, with important cities at the center, relying on expressway transportation corridors to expand into the surrounding central towns and core scenic areas. However, the large flow of tourists between the core city and the core scenic area has resulted in a severe polarization of passenger flows in the geographic center. The geographically disadvantaged nodes are often distributed in the peripheral areas of the overall network, relying on the input of other provincial passenger flows and radiation into the internal network to drive the surrounding towns, villages, and scenic areas where there are huge differences in passenger flow.

Finally, this study put forward seven types of expressway service area tourism utilization modes in the Guizhou expressway network (Figure 9), and suggestions are as follows:

(1) Transportation hub-type service areas: as a transportation hub, these should focus on promoting the construction of regional tourism distribution centers.

(2) Service areas relying on tourism attraction: these service areas should have close relationships with the surrounding tourist attractions, focusing on the core tourist attractions nearby so as to realize the integrated linkage development of the service area and those tourist attractions.

(3) Tourism gateway-type service areas: these service areas are location adjacent to service areas at the junction of provinces and cities and should focus on shaping the local tourism "image window" and providing information consulting services.

(4) Secondary gateway-type service areas: development of these service areas will mean taking tourism gateway-type service areas and connecting them with other service areas in the province internally, which should strengthen traffic utilization services and tourism information services, such as real-time transportation, urban display, and other tourism services.

(5) Urban leisure-type service areas: based on urban leisure needs, the construction of comprehensive service facilities such as large-scale stores and 
professional markets should be promoted, and these should be developed into urban leisure areas.

(6) Rural leisure-type service areas: to develop these types of services areas, by relying on the characteristic agricultural resources around the service area, the surrounding villages should be linked, rural tourism activities should be carried out, and urban rural leisure tourism destinations should be built.

(7) Community co-construction and sharing-type service areas: the development of the service area in conjunction with the surrounding ethnic villages should be promoted, and the service area should be made a comprehensive service center for local communities, an exhibition center for the trade of agricultural products, and an exhibition center for the cultural heritage of ethnic minorities.

4.2.1. Significance. Research on complex transportation networks combines complexity science with transportation science, and expressways are a form of complex transportation networks. Therefore, this study is significant because

(1) Domestic and foreign studies on complex transportation networks have mostly been conducted from the perspective of railways [46], air transportation [33], and urban transportation [24] but seldom on expressway transportation networks. Hence, this study enriches the knowledge on complex transportation networks.

(2) This study broadens the scope for the practical application of complexity research on transportation networks by analyzing the spatial structural characteristics of a transportation network and innovatively performing the coupled clustering of geographical centrality and passenger flow centrality to quantitatively analyze the differences between geographical advantage and actual passenger flow advantage.

(3) A comprehensive indicator was calculated using factor analysis to uniformly characterize the transportation convenience, accessibility, and intermediation of expressway service areas using geographical centrality. This approach enabled us to avoid problems caused by scattered indicators' inability to holistically reflect the spatial structural characteristics of transportation networks.

(4) This study proposed seven development models that have practical significance in guiding the upgrade and transformation of service areas for optimizing the layout of the expressway transportation network and promoting the composite use of expressway service areas for tourism.

4.2.2. Limitations. In this study, complex network theory, social network analysis, kernel density analysis, and bivariate autocorrelation were employed to analyze the complexity of the Guizhou expressway transportation network and the tourism utilization potential of expressway service areas.

Due to limitations of the data, we cannot deduce the influence of the evolution of the Guizhou expressway traffic network in terms of its tourism utilization potential across time. We merely discuss its static structure characteristics. In the future, however, we will carry out dynamic evolution and simulation prediction research on the complex traffic network and its tourism utilization potential. In addition, this study still leaves room for additional improvement in the understanding of the complexity of transportation networks. It does not take into consideration the impact of aviation, railway, urban transportation, and other transportation networks on tourism utilization potential nor does it account for the impact of urban and rural self-attraction. In the future, we will focus on the impact of the interaction of multiple transportation elements and spatial elements on the tourism utilization potential, as well as complex transportation. The comprehensive influence of the communication network structure on the development orientation of the spatial structure of the tourism destination is the key issue to be explored in future research.

\section{Data Availability}

The prior studies are cited at relevant places within the text as references [1-59]. The degree, closeness, betweenness, geographical centrality data, and passenger-car flow rates of expressway service areas in Guizhou province used to support the findings of this study are included within the paper.

\section{Conflicts of Interest}

The authors declare that there are no conflicts of interest regarding the publication of this paper.

\section{Acknowledgments}

This study was supported by the National Natural Science Foundation of China, "Simulation Study on the Spatial Evolution Model and System Optimization of Tourism Urbanization" (no. 41671151).

\section{References}

[1] J. Xi and M. Liu, "Analysis of basic national conditions of China's tourism industry," Journal of Natural Resources, vol. 34, pp. 1569-1580, 2019.

[2] S. Porta, P. Crucitti, and V. Latora, "The network analysis of urban streets: a primal approach," Environment and Planning B: Planning and Design, vol. 33, no. 5, pp. 705-725, 2006.

[3] A. Sevtsuk and M. Mekonnen, "Urban network analysis: a new toolbox for measuring city form in ArcGIS," in Proceedings of the 2012 Symposium on Simulation for Architecture and Urban Design, pp. 114-126, Society for Computer Simulation International, San Diego, CA, USA, March 2012.

[4] C. Cooper, Spatial Design Network Analysis (sDNA) Version 3.3 Manual, Cardiff University, Cardiff, UK, 2016. 
[5] Y. T. Mohmand and A. Wang, "Complex network analysis of Pakistan railways," Discrete Dynamics in Nature and Society, vol. 2014, Article ID 126261, 5 pages, 2014.

[6] A. Pagani, G. Mosquera, A. Alturki et al., "Resilience or robustness: identifying topological vulnerabilities in rail networks," Royal Society Open Science, vol. 6, no. 2, Article ID 181301, 2019.

[7] Z. Xu and R. Harriss, "Exploring the structure of the U.S. intercity passenger air transportation network: a weighted complex network approach," GeoJournal, vol. 73, pp. 87-102, 2014.

[8] D. Tsiotas and S. Polyzos, "Decomposing multilayer transportation networks using complex network analysis: a case study for the Greek aviation network," Journal of Complex Networks, vol. 3, no. 4, pp. 642-670, 2015.

[9] Q. H. A. Tran and A. Namatame, "Worldwide aviation network vulnerability analysis: a complex network approach," Evolutionary and Institutional Economics Review, vol. 12, no. 2, pp. 349-373, 2015.

[10] E. Tranos, "The topology and the emerging urban geographies of the internet backbone and aviation networks in Europe: a comparative study," Environment and Planning A: Economy and Space, vol. 43, no. 2, pp. 378-392, 2011.

[11] P. Crucitti, V. Latora, and S. Porta, "Centrality measures in spatial networks of urban streets," Physical Review E: Covering Statistical, Nonlinear, Biological, and Soft Matter Physics, vol. 73, Article ID 36125, 2006.

[12] S. Porta, V. Latora, F. Wang et al., "Street centrality and the location of economic activities in Barcelona," Urban Studies, vol. 49, no. 7, pp. 1471-1488, 2012.

[13] Z. Tian, L. Jia, H. Dong, F. Su, and Z. Zhang, "Analysis of urban road traffic network based on complex network," Procedia Engineering, vol. 137, pp. 537-546, 2016.

[14] S. Yang, X. Liu, Y.-J. Wu, J. Woolschlager, and S. L. Coffin, "Can freeway traffic volume information facilitate urban accessibility assessment?” Journal of Transport Geography, vol. 44, pp. 65-75, 2015.

[15] R. Ding, N. Ujang, H. B. Hamid et al., "Application of complex networks theory in urban traffic network researches," Networks and Spatial Economics, vol. 19, no. 4, pp. 1281-1317, 2019.

[16] F. Jin and Z. Chen, "Evolution of transportation in China since reform and opening up: patterns and principles," Journal of Geographical Sciences, vol. 29, no. 10, pp. 17311757, 2019.

[17] Y. Chen, F. Jin, Y. Lu, Z. Chen, and Y. Yang, "Development history and accessibility evolution of land transportation network in Beijing-Tianjin-Hebei region over the past century," Journal of Geographical Sciences, vol. 28, no. 10, pp. 1500-1518, 2018.

[18] J. Yang, J. Sun, H. Zhao, J. Xi, and X. Li, "Spatio-temporal differentiation of residential land for coastal town: a case study of dalian jinshitan," Chinese Geographical Science, vol. 26, no. 4, pp. 566-576, 2016.

[19] J. Yang, A. Guo, X. Li, and T. Huang, "Study of the impact of a high-speed railway opening on China's accessibility pattern and spatial equality," Sustainability, vol. 10, no. 8, p. 2943, 2018.

[20] J. Wang, H. Mo, and F. Jin, "Spatial structural characteristics of Chinese aviation network based on complex network theory," Acta Geographica Sinica, vol. 64, pp. 899-910, 2009.

[21] X. Wu and S. Man, "Air transportation in China: temporal and spatial evolution and development forecasts," Journal of Geographical Sciences, vol. 28, no. 10, pp. 1485-1499, 2018.
[22] Y. Xing, J. Lu, S. Chen, and S. Dissanayake, "Vulnerability analysis of urban rail transit based on complex network theory: a case study of Shanghai metro," Public Transport, vol. 9, no. 3, pp. 501-525, 2017.

[23] H. Cao, F. Zhao, H. Liu, and T. Yu, "The impact of subway on urban traffic network based on complex network theory," MATEC Web of Conferences, vol. 61, p. 4025, 2016.

[24] C. Du, J. Wang, B. Liu, and D. Huang, "Impacts of street and public transport network centralities on housing rent: a case study of Beijing," Progress in Geography, vol. 38, no. 12, pp. 1831-1842, 2019.

[25] Z. Xu and B. Chen, "Study on node importance evaluation of the high-speed passenger traffic complex network based on the structural hole theory," Open Physics, vol. 15, no. 1, pp. 1-11, 2017.

[26] R. Ding, "The complex network theory-based urban land-use and transport interaction studies," Complexity, vol. 2019, Article ID 4180890, 14 pages, 2019.

[27] W. Dougill, "Regional plan of New York and its environs: Highway traffic (book review)," Town Planning Review, vol. 12, no. 2, pp. 145-147, 1926.

[28] D. R. Judd, "Promoting tourism in US cities," Tourism Management, vol. 16, no. 3, pp. 175-187, 1995.

[29] G. I. Crouch, "Demand elasticities for short-haul versus longhaul tourism," Journal of Travel Research, vol. 33, no. 2, pp. 2-7, 1994.

[30] T. Bieger and A. Wittmer, "Air transport and tourism-perspectives and challenges for destinations, airlines and governments," Journal of Air Transport Management, vol. 12, no. 1, pp. 40-46, 2006.

[31] D. M. Spencer, "Airport stops and flights on small airplanes as inhibitors of tourism-related air travel: a case study," Tourism Management, vol. 30, no. 6, pp. 838-846, 2009.

[32] S. A. Rehman Khan, D. Qianli, W. SongBo, K. Zaman, and Y. Zhang, "Travel and tourism competitiveness index: the impact of air transportation, railways transportation, travel and transport services on international inbound and outbound tourism," Journal of Air Transport Management, vol. 58, pp. 125-134, 2017.

[33] A. Papatheodorou and P. Arvanitis, "Spatial evolution of airport traffic and air transport liberalisation: the case of Greece," Journal of Transport Geography, vol. 17, no. 5, pp. 402-412, 2009.

[34] C. A. Vogt, "Multi-destination trip patterns," Annals of Tourism Research, vol. 24, pp. 458-461, 1997.

[35] A. Lew and B. McKercher, "Modeling tourist movements," Annals of Tourism Research, vol. 33, no. 2, pp. 403-423, 2006.

[36] S. Page and J. Connell, "Exploring the spatial patterns of carbased tourist travel in loch lomond and trossachs national park, Scotland," Tourism Management, vol. 29, pp. 561-580, 2008.

[37] K. Thompson and P. Schofield, "An investigation of the relationship between public transport performance and destination satisfaction," Journal of Transport Geography, vol. 15, no. 2, pp. 136-144, 2007.

[38] P. Peeters, E. Szimba, and M. Duijnisveld, "Major environmental impacts of European tourist transport," Journal of Transport Geography, vol. 15, no. 2, pp. 83-93, 2007.

[39] M. Brtnický, V. Pecina, M. V. Galiová et al., "The impact of tourism on extremely visited volcanic island: link between environmental pollution and transportation modes," Chemosphere, vol. 249, p. 126118, 2020.

[40] F. Deng, Y. Fang, L. Xu, and Z. Li, “Tourism, transportation and low-carbon city system coupling coordination degree: a 
case study in Chongqing municipality, China," International Journal of Environmental Research and Public Health, vol. 17, no. 3, p. 792, 2020.

[41] K. S. Bunds, J. M. Casper, J. A. Hipp, and J. Koenigstorfer, "Recreational walking decisions in urban away-from-home environments: the relevance of air quality, noise, traffic, and the natural environment," Transportation Research Part F: Traffic Psychology and Behaviour, vol. 65, pp. 363-375, 2019.

[42] D. A. Jiménez-Uribe, D. Daniels, Á. González-Álvarez, and A. M. Vélez-Pereira, "Influence of vehicular traffic on environmental noise spectrum in the tourist route of santa marta city," Energy Reports, vol. 6, pp. 818-824, 2019.

[43] J. E. Dickinson, S. Calver, K. Watters, and K. Wilkes, "Journeys to heritage attractions in the UK: a case study of national trust property visitors in the south west," Journal of Transport Geography, vol. 12, no. 2, pp. 103-113, 2004.

[44] Z. Wang, "On several characteristics of tourism transportation in China and its development direction," Tourism Tribune, vol. 3, pp. 35-40, 1989.

[45] J. Bao and Y. Chu, Tourism Geography, Higher Education Press, Beijing, China, 1999.

[46] S. B. Wang, X. L. Luo, J. H. Guo, P. G. Zhang, and Z. N. Gu, "Dynamic evolution of tourism spatial structure under the improvement of the high speed rail network in northeast China," Scientia Geographica Sinica, vol. 39, pp. 568-577, 2019.

[47] S. Jin, J. Yang, E. Wang, and J. Liu, "The influence of highspeed rail on ice-snow tourism in northeastern China," Tourism Management, vol. 78, Article ID 104070, 2020.

[48] Y. T. Yang, R. K. Zhang, Y. R. An, and J. Z. Wu, "Steady vortex force theory and slender-wing flow diagnosis," Acta Mechanica Sinica, vol. 23, no. 6, pp. 609-619, 2007.

[49] Z. Yang, M. Yin, J. Xu, and W. Lin, "Spatial evolution model of tourist destinations based on complex adaptive system theory: a case study of southern Anhui, China," Journal of Geographical Sciences, vol. 29, no. 8, pp. 1411-1434, 2019.

[50] W. Pu and T. Mi, "On estimating transportation energy consumption and carbon dioxide emissions from off-shore island tourism-a case study of Haikou city, China," Journal of Resources and Ecology, vol. 7, no. 6, pp. 472-479, 2016.

[51] B. Wu and M. Li, "EDVAET: A linear landscape evaluation technique-a case study on the Xiaoxinganling scenery drive," Acta Geographica Sinica, vol. 2, pp. 214-222, 2001.

[52] L. C. Freeman, "Centrality in social networks conceptual clarification,” Social Networks, vol. 1, no. 3, pp. 215-239, 1978.

[53] E. Kreyszig, Advanced Engineering Mathematics, Wiley, Hoboken, NJ, USA, 4th edition, 1979.

[54] M. Rosenblatt, "Remarks on some nonparametric estimates of a density function," The Annals of Mathematical Statistics, vol. 27, no. 3, pp. 832-837, 1956.

[55] E. Parzen, "On estimation of a probability density function and mode," The Annals of Mathematical Statistics, vol. 33, no. 3, pp. 1065-1076, 1962.

[56] K. Dehnad and B. Silverman, "Density estimation for statistics and data analysis," Technometrics, vol. 29, p. 495, 1986.

[57] M. F. Goodchild, Spatial Autocorrelation, Geo Books, Norwich, UK, 1986.

[58] L. Anselin, "Local indicators of spatial association-lisa," Geographical Analysis, vol. 27, pp. 93-115, 1995.

[59] H. H. Mo, F. J. Jun, Y. Liu, and J. E. Wang, "Network analysis on centrality of airport system," Scientia Geographica Sinica, vol. 30, pp. 204-212, 2010. 